\title{
Crashworthiness Analysis and Multi-Objective Optimisation of Multi-Cell Windowed Structures under Dynamic Impact Loading
}

\author{
Jiehao Chen $\mathbb{D}^{1,2,3}$ Xifeng Liang, ${ }^{1,2,3}$ Ping $X u^{1,2,3}$ and Shuguang Yao $\mathbb{D}^{1,2,3}$ \\ ${ }^{1}$ Key Laboratory of Traffic Safety on Track, Ministry of Education, School of Traffic \& Transportation Engineering, \\ Central South University, Changsha 410075, China \\ ${ }^{2}$ Joint International Research Laboratory of Key Technology for Rail Traffic Safety, Central South University, \\ Changsha 410075, China \\ ${ }^{3}$ National \& Local Joint Engineering Research Center of Safety Technology for Rail Vehicle, Central South University, \\ Changsha 410075, China
}

Correspondence should be addressed to Shuguang Yao; ysgxzx@csu.edu.cn

Received 13 July 2021; Revised 21 November 2021; Accepted 11 December 2021; Published 31 January 2022

Academic Editor: Thanh-Phong Dao

Copyright (C) 2022 Jiehao Chen et al. This is an open access article distributed under the Creative Commons Attribution License, which permits unrestricted use, distribution, and reproduction in any medium, provided the original work is properly cited.

Applying a windowed design in a thin-walled structure is a method to further enhance the crashworthiness of the structure. In this study, two kinds of windowed designs were introduced into different regions of a multi-cell energy absorption structure to form a multi-cell windowed structure, and its crashworthiness under dynamic impact was studied. Dynamic impact testing and LSDYNA finite element modelling were combined to calculate the crashworthiness response of the structure. The simulation results show that the use of the windowed multi-cell structure can improve the crashworthiness response of the multi-cell structure. The influence of the windowed design on the structural deformation mode was analysed in detail. In addition, the multi-objective optimization design of different windowed structures was carried out to obtain a comprehensive crashworthiness evaluation, and the results show that the windowed design at the front end of the structure yields good results regarding the initial peak force (PCF), while the windowed design in the middle of the structure can effectively improve the specific energy absorption (SEA) and energy absorption (EA).

\section{Introduction}

Thin-walled structures are widely used as energy absorbers in aircraft, automotive vehicles, and vehicles due to their superior performance and economy [1]. As the main component of passive safety, thin-walled energy-absorbing structure must have the characteristics of low peak load, controllable deformation mode, and high energy absorption efficiency. Thin-walled structures are studied from simple circular, square, triangular, polygonal, and other conventional structures [2-6]; the deformation mode of conventional structures was studied in detail by experiment and theory. Based on these, various methods have been used to improve the mechanical properties of traditional tubes, including multi-cornered section structure [7], corrugated tubes [8-10], multi-cell structure [11], nested tubular structures [12-14], filling tubes with foam $[15,16]$, honeycomb structure based on bionic design [17-20], and variable thickness design [21-24]. However, in the process of improving the performance, the deformation mode of some structures is unstable, which does not make the maximum energy absorption efficiency of the material. In addition, the larger peak force also needs to be improved.

Researchers have tried to use induction design to improve the above problems. The purpose of the induction design is to reduce the peak force and induce specific deformation modes by setting imperfections in some areas. In an early stage, Gupta and Gupta [25] studied the crashworthiness of windowed circular tubes through experiments and found that the windowed design can reduce the peak force and improve the deformation stability of longer structures. Wang et al. [26] and Zhou et al. [27] use origami patterns as an induction design. They placed the induction design at the front end and the walls of the structure, 
respectively. Li et al. [28] compared two different induction methods of pressing a stamp and windowed. Their research showed that the energy absorption of the windowed method is higher than that of the pressing method under axial impact. Song et al. [29-31] studied the crashworthiness behaviour of thin-walled square tubes with patterned windows. The authors added a number of square windowed holes to the energy-absorbing structure and studied the size of the holes. The result is that the windowed structure can improve the deformation mode and the peak force of the structure. However, the large hole leads to the decrease in energy absorption. Nikkhah et al. [32] studied the number of windows in the structure and found that the size and distribution of windows had a great influence on the energy absorption characteristics of the structure.

All these previous studies indicate that the energy absorption structures considering a windowed design method are generally superior to the counterpart in crashworthiness. However, these studies focus on the shape and size of window design and compare the effects of different opening schemes on deformation mode and crashworthiness. The influence mechanism of window design on the structure needs to be further studied. In this work, the finite element model of the multi-cell structure is established for energy absorption performance analysis, which is verified by experiments. Thereafter, numerical simulations are conducted to investigate the crashworthiness of the front-end and middle windowed tubes under dynamic impact, and the relationship between stress distribution and deformation mode of different windowed structures is analysed. The multi-objective optimization problem of the windowed structure is solved using the multi-objective genetic algorithm (MOGA) to maximize the SEA and minimize the PCF, and the results show that the windowed design at the front end of the structure yields good results regarding the initial peak force, while the windowed design in the middle of the structure can effectively improve the specific energy absorption and energy absorption.

\section{Geometry of the Multi-Cell Structure and Finite Element Model}

2.1. Geometry of the Multi-Cell Structure. As indicated in Figure 1, the multi-cell structures studied in this study are composed of four ortho hexagonal tubes of the same size connected by edges. Hexagons are placed in an area connected by four edges. In this study, the region composed of four hexagons and four sides is called the inner cell, and the four hexagon cells are called the outer cell. The connecting edge, which is $150^{\circ}$ to the hexagon, is defined as the side column, and its length is $51 \mathrm{~mm}$. The connecting edge, which is $120^{\circ}$ to the hexagon, is defined as the corner column, and its length is $56 \mathrm{~mm}$.

In this study, the corner column and side column of the structure have a windowed design as this design has different effects on the EA performance [33]. There are two kinds of windowed structures: square windowed structure and circular windowed structure. The shape of the single-hole structure is square and located at the front end of the

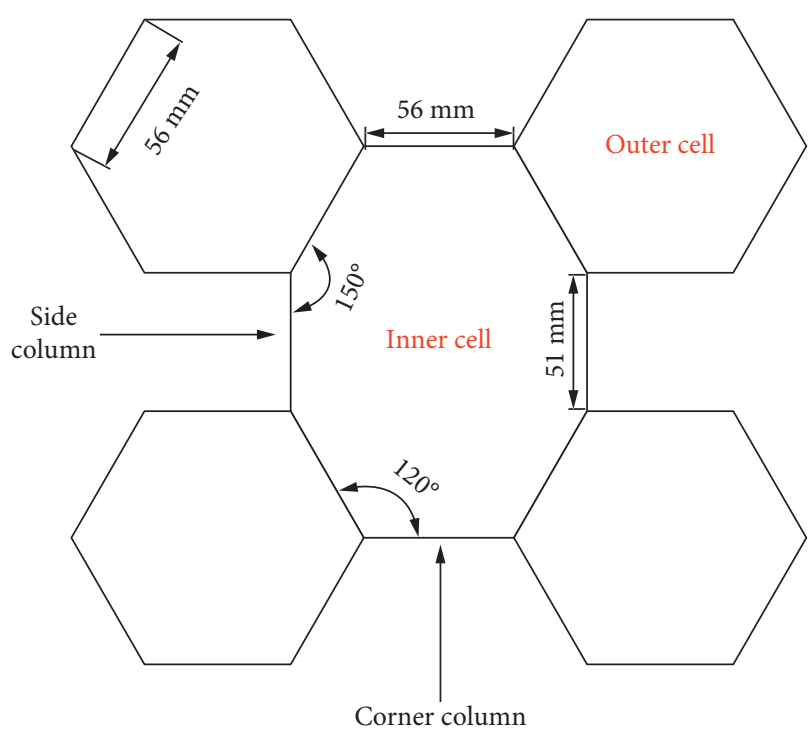

Figure 1: Cross-sectional shape of the multi-cell structure.

structure. The shape of the multi-hole structure is circular and located at the middle of the structure. The distance between the centers of the two circles is twice the distance from the center of the first circle to the front end. Finally, six research objects were formed as shown in Figure 2. To distinguish the different structures, each structure was assigned a name according to its characteristics, which are original multi-cell structure (MC), multi-cell structure with square windowed in multicolumn (MCS-M), multi-cell structure with square windowed in corner column (MCS-C), multi-cell structure with square windowed in side column (MCS-S), multi-cell structure with circle windowed in corner column (MCC-C), and multi-cell structure with circle windowed in side column (MCC-S). The detailed parameters, shape, and name of the structure are shown in Figure 3. When the thickness is $5 \mathrm{~mm}$, the structure needs approximately $80 \mathrm{~mm}$ to produce a fold. The initial distance of the windowed design was $40 \mathrm{~mm}$; at this time, six circular holes can be placed in the structure.

2.2. Finite Element Model. In this study, the crashing behaviour of the multi-cell energy-absorbing structure under dynamic impact loads was modelled using the explicit nonlinear finite element package LS-DYNA. As shown in Figure 3, the finite element model (FEM) is constructed with four main components: the energy-absorbing structure (Figure 4), the crash trolley, standard tracks, and a fixed rigid wall.

In the analysis process, based on mesh convergence analysis model, the different element sizes ranging from $4 \mathrm{~mm}$ to $10 \mathrm{~mm}$ were considered. The EA curves of thinwalled tube are shown in Figure 5. It appears that the results converged when element size is $5 \mathrm{~mm}$. Therefore, the multicell energy-absorbing structure is modelled using Belytschko-Tsay quadrilateral shell elements of $5 \mathrm{~mm} \times 5 \mathrm{~mm}$, which use four-node shell elements with three integration points through the thickness and one integration 

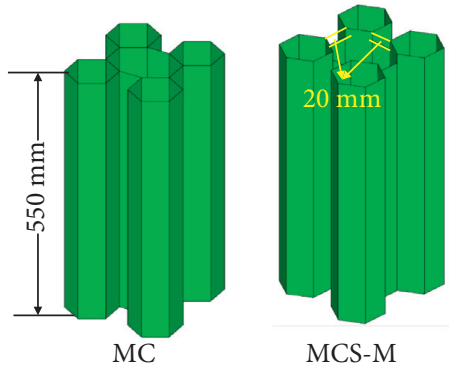

(a)

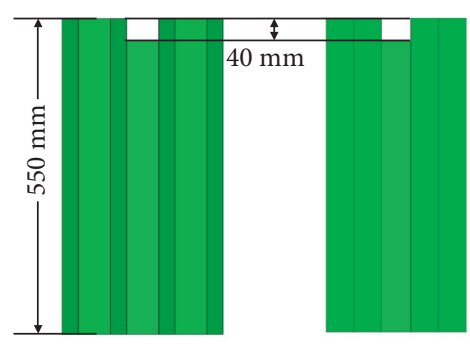

MCS-S

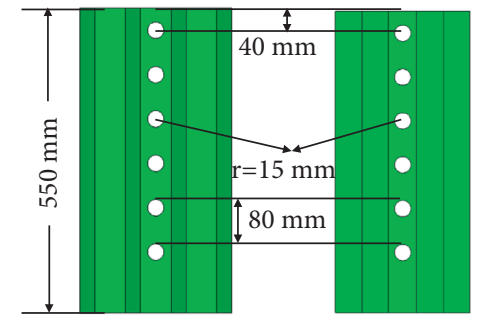

MCC-C
MCC-S

(c)

FIGURE 2: The windowed structures at different positions in the experimental study. (a) Multi-cell structure. (b) Square windowed structure. (c) Circular windowed structure.

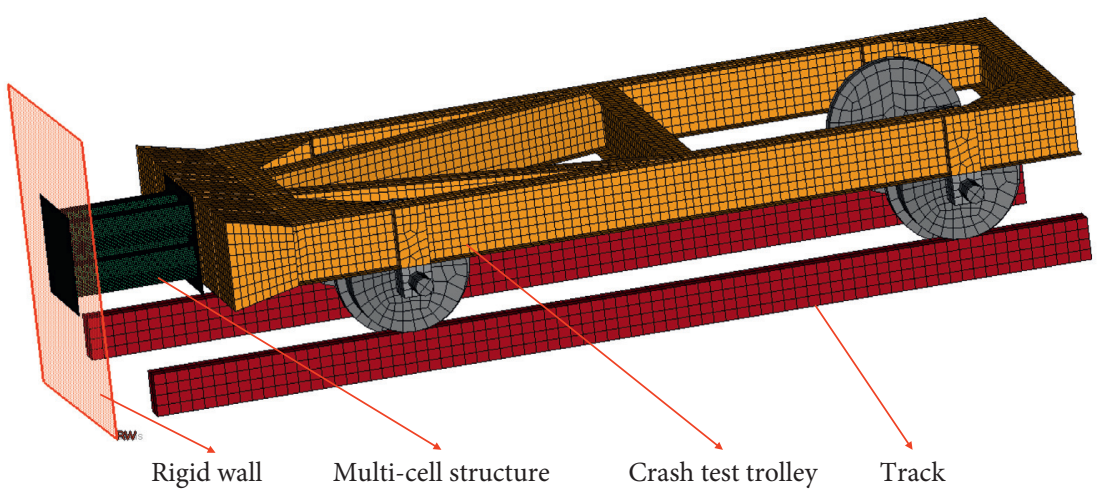

FIgURE 3: FEM and boundary conditions.

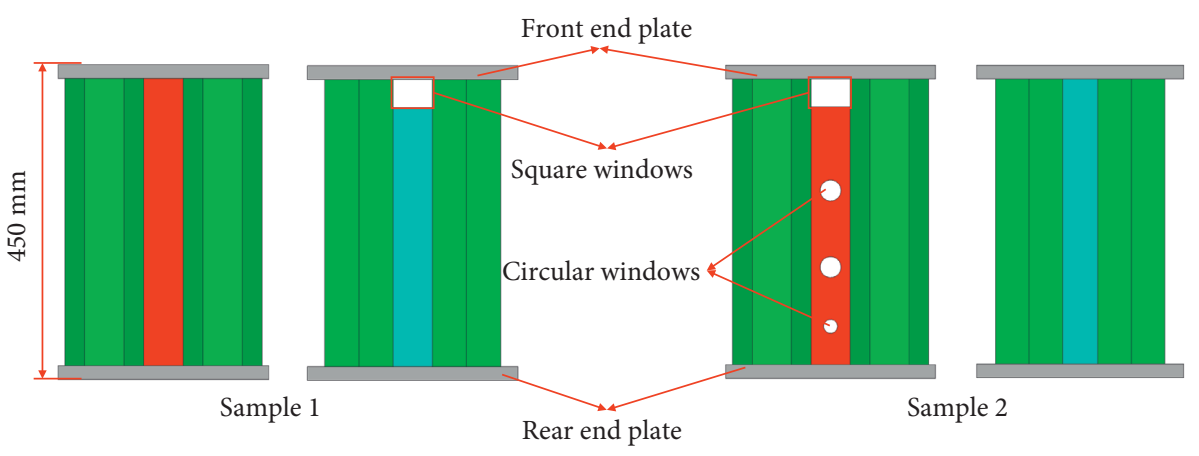

FIGURE 4: Shapes of the samples used for FEM validation.

point in the element plane. The front-end plate and rear-end plate of the structure are modelled using solid elements. Additionally, a $30 \mathrm{~mm} \times 30 \mathrm{~mm}$ unit is used for the test trolley and a $40 \mathrm{~mm} \times 40 \mathrm{~mm}$ unit is used for the standard tracks to reduce the computational load [34]. The "AUTOMATIC SINGLE SURFACE" contact algorithm is applied for the self-contact of the energy-absorbing structure, and the "AUTOMATIC SURFACE TO SURFACE" contact algorithm is applied for the contact between the energyabsorbing structure, the test trolley, and the tracks. The static coefficient of friction is defined as 0.3 , and the dynamic coefficient of friction is defined as 0.1 [35]. The standard tracks are fully constrained, and the gravity acceleration is set to $9.8 \mathrm{~N} / \mathrm{kg}$ during the whole process. The test trolley, with a mass of 2 tons, impacts a fixed rigid wall at an initial velocity that is equal to the measured velocity during the impact experiment. The mechanical properties of this material according to reference [34] are density $\rho=2700 \mathrm{~kg} / \mathrm{m}^{3}$, Young's modulus $E=72000 \mathrm{MPa}$, Poisson's ratio $\mu=0.3$, yield stress $\sigma y=131.82 \mathrm{MPa}$, and ultimate tensile stress $\sigma u$ $=190.68 \mathrm{MPa}$. MAT $24(*$ MAT $24 *$ MAT PIECEWISE LINEAR PLASTICITY) is chosen from LS_DYNA to define the material of the multi-cell energy-absorbing structure.

2.3. Validation of the FEM. To verify the correctness of the finite element model, impact tests were carried out on samples 1 and 2 . The energy absorption structure is fixed on 


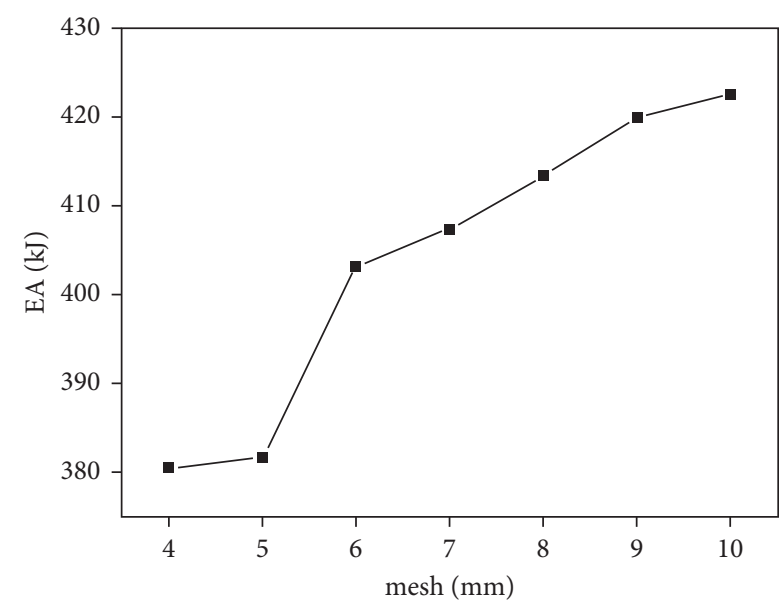

Figure 5: Influence of element size on EA curve.

the test trolley through four 20 bolts to ensure that the test conditions are consistent with the finite element model. The weight of the test trolley is $2000 \mathrm{~kg}$. The large tonnage force sensor is arranged on the rigid wall to collect the impact force. The test speed is recorded by a laser velocimeter. The impact velocities of sample 1 and sample 2 are $15.51 \mathrm{~m} / \mathrm{s}$ and $15.30 \mathrm{~m} / \mathrm{s}$, respectively.

Figure 6 shows the force-time curves and deformation results for samples 1 and 2. The force-time curves of the test and simulation show the same trend at the key positions. The deformation result and force-time curve show good consistency. The final deformation modes of the test and simulation are consistent. Considering the complexity of the impact test and the error of industrial manufacturing, the test and simulation cannot be completely consistent, so some differences are acceptable. Table 1 lists the comparison of PCF, duration, and EA in test and simulation. It can be seen that the relative errors of sample 1 in the three key parameters are $-4.56 \%$, $-2.01 \%$, and $0.70 \%$ respectively, while sample 2 in the three key parameters are $-2.67 \%, 3.02 \%$, and $0.21 \%$ respectively. Therefore, the finite element model in this study can be regarded as an accurate model and can be used to further study the effect of windowed multi-cell structures.

\section{Crashworthiness Performance Analysis of the Windowed Structures}

3.1. Crashworthiness Index. The energy-absorbing structure of the fore-end of a high-speed train absorbs the kinetic impact energy mainly through compression deformation when a collision occurs. To assess the crashing performance of a thin-walled structure, structural crashworthiness indexes should be defined. The structural crashworthiness indexes used are as follows:

Energy absorption (EA): a typical indicator for evaluating an energy-absorbing structure is the energy absorption, which can be integrated with the impacting forcedisplacement curve as:

$$
E A=\int_{0}^{s} F(s) \mathrm{d} s .
$$

Peak crushing force (PCF) indicates the maximum value of $F(s)$ during the initial stage of a collision process. A high PCF always brings large injuries to passengers, so the smaller $\mathrm{PCF}$ is, the better the structure.

Specific energy absorption (SEA): in the crashworthiness design of an energy-absorbing structure, this parameter is the crash energy absorbed per unit mass of the thin-walled member. The SEA is defined as:

$$
\begin{aligned}
\text { SEA } & =\frac{E A}{m} \\
& =\frac{\int_{0}^{s} F(s) \mathrm{d} s}{m},
\end{aligned}
$$

where $m$ is the mass of the energy absorber. In the design of the crashworthiness of thin-walled structures, the value of SEA shows the utilization of the thin-walled structure in the EA. The SEA represents the energy absorption efficiency of the absorber; a high SEA is always preferred.

There are some differences in the crushing displacement of different structures. The same compression value cannot be selected in the evaluation of the crashworthiness of different structures. In this study, the energy efficiency $(f)$ [36] is used to measure the EA of different structures before crushing. $f$ is defined as:

$$
\begin{aligned}
f & =\frac{E A}{F_{\max }} \\
& =\frac{\int_{0}^{s} F(s) \mathrm{d} s}{F_{\max }},
\end{aligned}
$$

where $F$ is the axial crushing force and $F_{\max }$ denotes the maximum crush force in the interval $[0, s]$ except the PCF. The $f$ is obtained from the force-displacement curve, as shown in Figure 7. During the folding process of energy-absorbing structure, EA, displacement, and $f$ increase approximately linear. When the compression reaches the compaction stage, the compression force increases sharply, while the displacement change is small, and $f$ will have a maximum value. At this time. It is considered that the structure reaches the maximum EA under the compression displacement. This formula is used to calculate the EA and SEA in this study.

3.2. Comparison of the Crashworthiness of the Different Windowed Structures. The FEM was used to simulate the different structures as shown in Figure 2. The crashworthiness of the different structures under the maximum $f$ calculated by formula 3 is listed in Table 2. It can be seen that the lowest EA is that of MC. For the windowed designs in the multi-cell structure, all windowed structures studied in this study can reduce the PCF and improve the SEA and offer better EA performance.

The deformation mode and stress distribution at different compression positions are shown in Figure 8, and the force-displacement curves of different structures are shown 

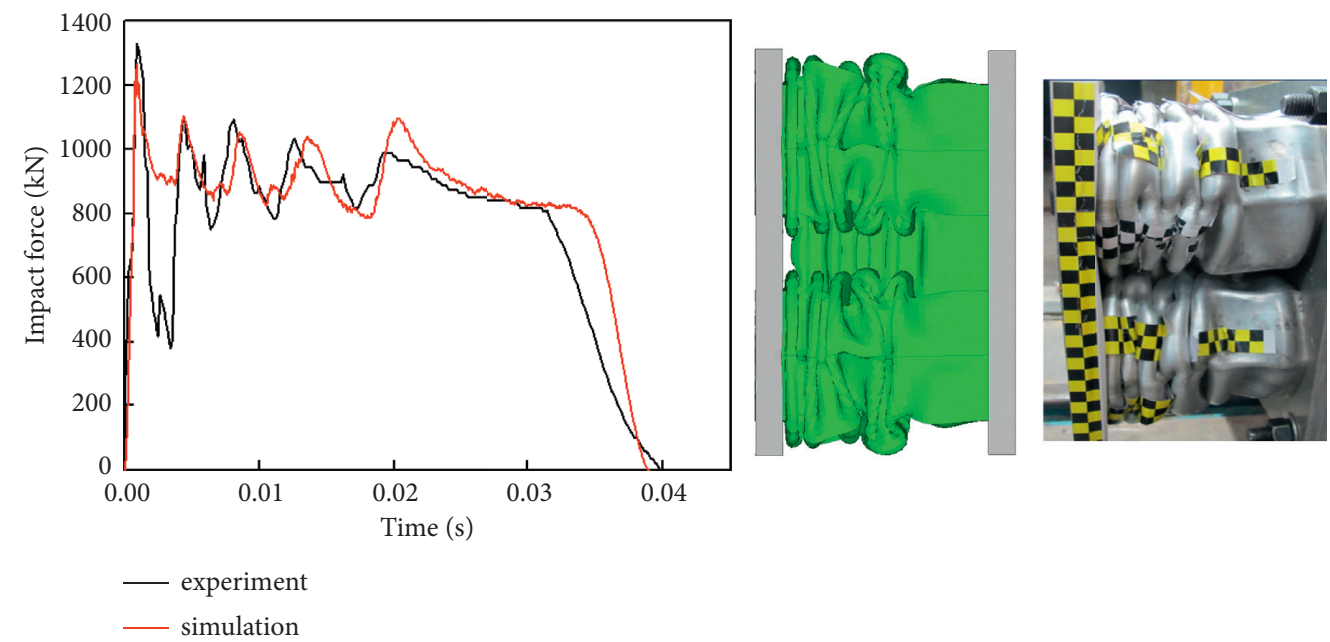

(a)
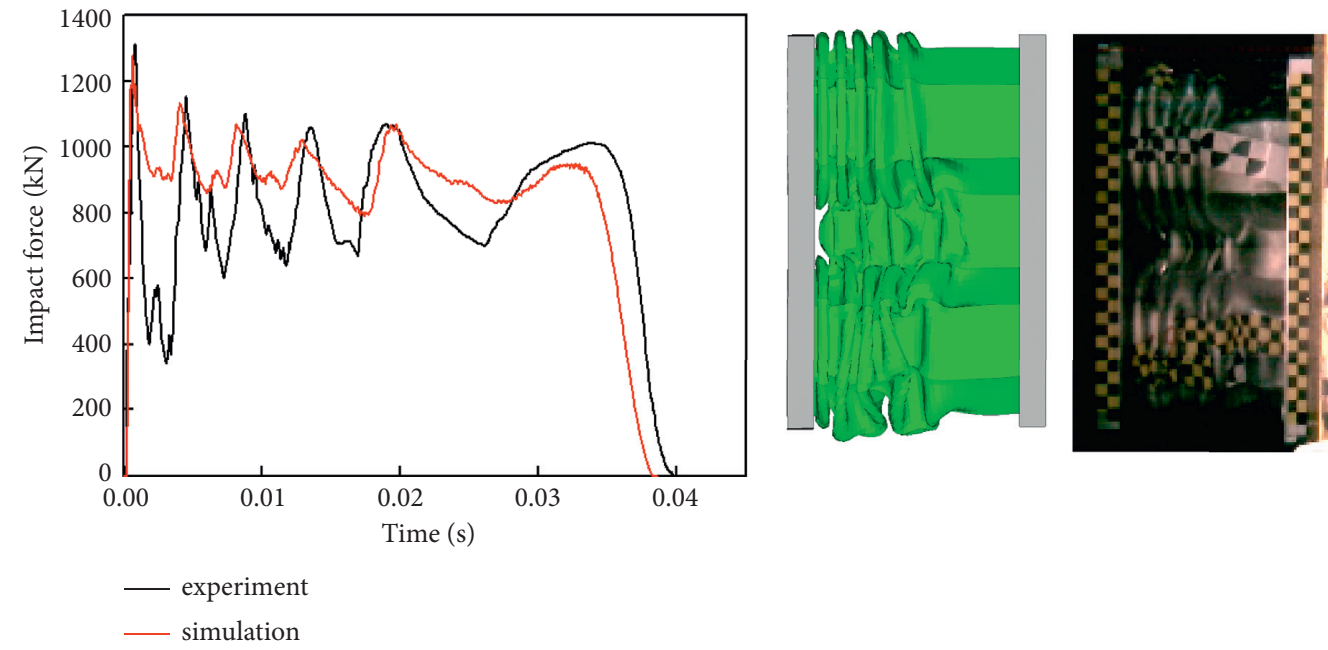

(b)

Figure 6: Comparison of experimental and simulation results. (a)Sample 1. (b)Sample 2.

TABle 1: Comparison of key parameters between test and simulation.

\begin{tabular}{lcccc}
\hline Parameters & PCF $(\mathrm{kN})$ & Time $(\mathrm{ms})$ & EA $(\mathrm{kN})$ & \\
\hline \multirow{4}{*}{ Sample 1 } & Test & 1327 & 39.8 & 242.9 \\
& FEM & 1266 & 39.0 & 244.6 \\
& Error $(\%)$ & -4.59 & -2.01 & 0.70 \\
\hline \multirow{3}{*}{ Sample 2 } & Test & 1311 & 39.7 & 235.5 \\
& FEM & 1276 & 38.5 & 236.0 \\
& Error $(\%)$ & -2.67 & -3.02 & 0.21 \\
\hline
\end{tabular}

in Figure 9. The crushing force of the structure reaches a peak value first and then fluctuates within a range. For the multi-cell structure with a circular windowed design, the peak force is also reduced, and the folding mode is similar to the square windowed structures. From the stress distribution during compression, the MC structure has a large stress at both ends of the structure and the form of overall buckling. This is the main reason for the large PCF of the structure. The stress of the outer cells of the square windowed structure gradually increases with the compression, and the inner cell appears stressed at the beginning of compression. For the circular window structure, the stress of the outer cells is between MC structure and square windowed structures, and the stress of the inner cell is lower than that of other types of structures. In addition, at the initial stage of folding, the stress center appears at the connection between edges, and the maximum stress of the structure occurs at the connection of the three sides, which makes the square windowed structure have the lowest PCF.

3.3. Analysis of the Influence of the Windowed Design on the Deformation Characteristics. In this section, the deformation characteristics of windowed structures are discussed. The cross section of the multi-cell structure is divided into four parts: the side column, corner column, inner wall, and outer wall. Because of the symmetry of the structure, the deformation of the symmetrical position is in agreement. These four parts can completely describe the deformation characteristics of the multi-cell structures. 


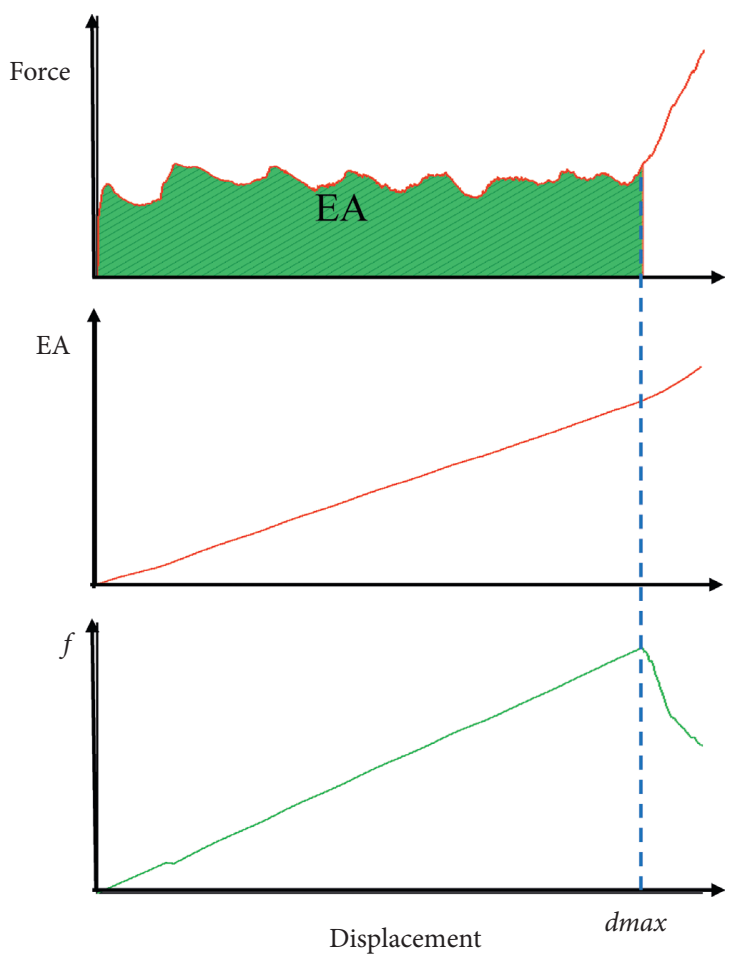

Figure 7: Relationship between $f$, EA, and force-displacement curve.

TABle 2: Crashworthiness index of the different multi-cell structures.

\begin{tabular}{lccc}
\hline Name & PCF $(\mathrm{kN})$ & EA $(\mathrm{kJ})$ & SEA $(\mathrm{kJ} / \mathrm{kg})$ \\
\hline MC & 1398.9 & 381.7 & 32.99 \\
MCS-C & 1282.2 & 400.3 & 34.78 \\
MCS-S & 1295.7 & 402.6 & 34.97 \\
MCS-M & 1238.9 & 386.7 & 33.60 \\
MCC-C & 1357.4 & 386.1 & 33.69 \\
MCC-S & 1355.0 & 386.0 & 33.68 \\
\hline
\end{tabular}

Figure 10 shows the cross-sectional view of the deformation of different windowed structures under numerical simulation. The middle position of the four parts is taken as the deformation result. Among them, the deformation result of the circular windowed design is discontinuous, which is caused by the existence of circular holes in the discontinuous position. To show the detailed deformation process, the missing lines are replaced by blue dotted lines. Note that the length of the dotted line is not equal to the diameter of the circular hole. For the MC structure without window design, 7 folds can be seen on the sidewall, corner wall, and inner wall of the structure, and the folding wavelength is similar. However, the number of folds on the outer wall of the structure is 4 , and the folding wavelength of each fold is inconsistent. The folding wavelength of the folds on the sidewall, corner wall, and inner wall of the windowed structure is similar to that of the MC structure, and the folding wavelength of the outer wall changes. The number of folds formed on the inner wall of all windowed structures is 7 . Two different numbers of folds distributed on the sidewall and corner wall are 7 and 6, respectively. The reason for the different numbers is that the length of the sidewall or corner wall of the square windowed structure is lower than that of the circular windowed structure. For the deformation characteristics of the outer wall, MCS-M has the shortest folding wavelength and the largest number of folds, and the number of folds of MCC-C and MCC-S is between that of MC and MCS-M. Through the folding characteristics of the structure, it can be seen that the windowed structure can improve the number of folds of the structure. The focus of this study is to increase the number of folds on the outer wall. Combined with the stress distribution and fold evolution model of different structures, the following conclusions can be obtained: the initial stress distribution under impact load is an important factor affecting the crashworthiness of structures, and reducing the impact of the initial stress on the nonfolded region of the structure is the key to improve the deformation stability of the outer wall.

\section{Research on the Crashworthiness of Windowed Structures and Multi-Objective Optimization}

4.1. Defining the Optimization Problems. In this study, SEA and PCF were selected as the crashworthiness criteria for evaluating the windowed structures. SEA is the index of the high efficiency and lightweight of the structure, which is maximized in the optimization design. The PCF is the safety index of vehicles and passengers, which is minimized in the optimization design to avoid possible serious injury. In the optimization design, there are four design variables: $L s, L c, r$, and $d$, which are the length of the square hole in the side column, the length of the square hole in the corner column, the radius of the circular hole, and the position of the hole in the structure, respectively. Where $2 d$ is the distance between the holes and $d$ is the distance from the first hole to the front end. The number of circular holes is constant at 6 (refer to Figure 11). The constraints of optimization are EA and thickness $(t)$. The EA of the windowed structure must be greater than that without the windowed structure. The thickness limit is considered from the lightweight of the structure. Therefore, the definition of the multi-objective optimization problem is shown in formula .

$$
\begin{cases}\min & (\mathrm{PCF},-\mathrm{SEA}) \\ & 10 \mathrm{~mm} \leq L s \leq 70 \mathrm{~mm}, \\ & 10 \mathrm{~mm} \leq L c \leq 70 \mathrm{~mm}, \\ \text { s.t. } & 30 \mathrm{~mm} \leq d \leq 45 \mathrm{~mm}, \\ & 5 \mathrm{~mm} \leq r \leq 25 \mathrm{~mm}, \\ & t \leq M C(t), \\ & E A(M C) \leq E A .\end{cases}
$$

The crashworthiness research of windowed structure is divided into three steps. The flow chart is shown in Figure 12. The detailed steps are as follows: 


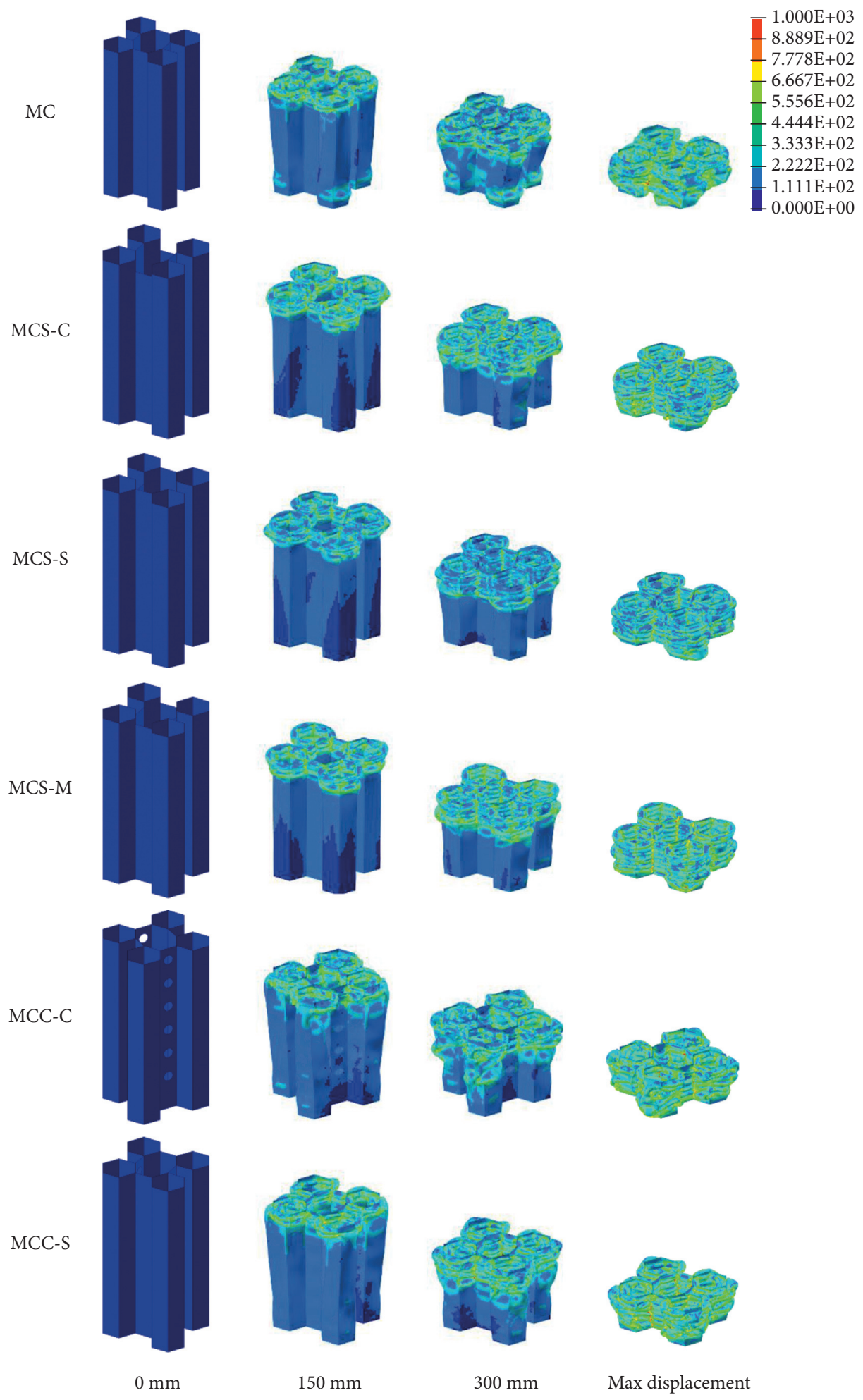

FIGURE 8: Finite element deformation models of the multi-cell structures.

(1) The radial basis function (RBF) model was used to construct the approximate model. In this step, the approximate models of MCS-C, MCS-S, MCS-M, MCC-C, and MCC-S are constructed respectively.

(2) The multi-objective genetic algorithm (MOGA) was used to find the optimal structure of the windowed multi-cell structures with thicknesses limited to $4 \mathrm{~mm}, 4.5 \mathrm{~mm}, 5 \mathrm{~mm}, 5.5 \mathrm{~mm}$, and $6 \mathrm{~mm}$, respectively. MOGA was used 25 times in total (5 different thicknesses and 5 different structures).

(3) Analyse and verify the optimization results. 


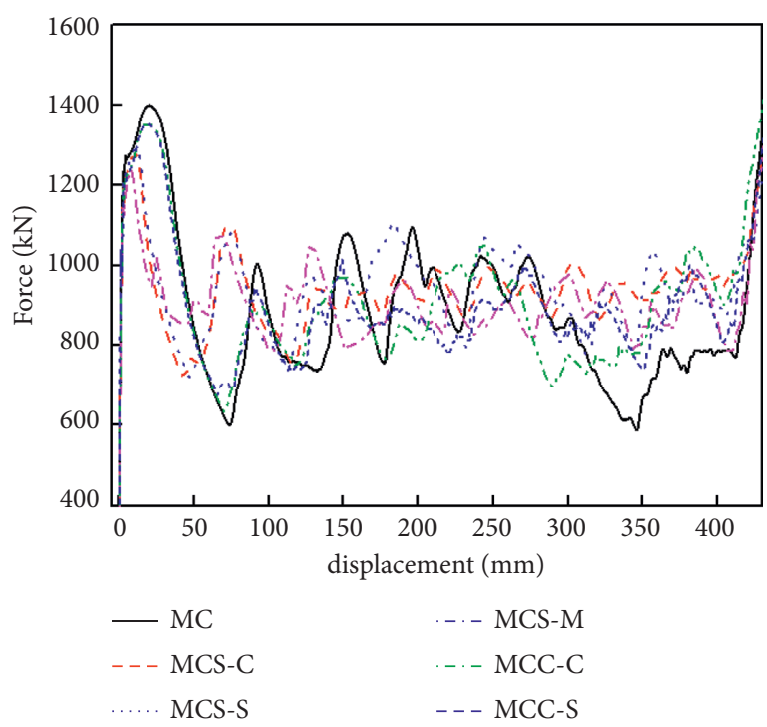

Figure 9: Force-displacement curves of different structures.

4.2. Radial Basis Function Model and Multi-Objective Genetic Algorithm. The RBF method is a kind of fitting method using a linear combination of basic functions. It can accurately fit the data through sampling points, and its residual value is very low. RBF has been proven to be effective and extensively used in the field of industrial optimization design [37]. The true function $y(x)$ [38] can be approximated as

$$
\widehat{y}(x)=\sum_{i=1}^{n} \lambda_{i} \varphi\left(\left\|x-c_{i}\right\|\right)+p(x),
$$

where $n$ is the number of sample points, $\lambda_{i}$ is the weight coefficient, $c_{i}$ denotes the ith center of basis functions, $p$ is a polynomial model, and $\varphi$ is a basis function and multi quadric used in the study. The relaxation coefficient of the basis function is 1 .

To ensure the accuracy of the RBF approximation model, the cross-validation method is adopted. For the adoption points used in the fitting, the boundary sampling points are generated by full factor design, and then the Latin hypercube design (LHD) is used to generate other sample points in the sampling space. Finally, the RBF is used for data fitting to generate an approximate model.

The accuracy of the model is evaluated by formulas 6-8 [39]. If the model accuracy does not reach a certain threshold, new sample points are added for another fit. When the accuracy of the model meets the requirements, the next step of multi-objective optimization solution is executed. The calculation formula of the evaluation index is as follows:

$$
\begin{aligned}
\operatorname{ARE} & =\frac{\sum\left|\widehat{y}_{i}-y_{i}\right| / y_{i}}{n} \times 100 \%, \\
\mathrm{MRE} & =\operatorname{Max}\left(\frac{\left|\widehat{y}_{i}-y_{i}\right|}{y_{i}} \times 100 \%\right),
\end{aligned}
$$

$$
R^{2}=1-\frac{\sum\left(\hat{y}_{i}-y_{i}\right)^{2}}{\sum\left(\hat{y}_{i}-y_{i}\right)^{2}}
$$

where $y_{i}$ is the real result of the numerical simulation, $\widehat{y}_{i}$ is the predicted value of the RBF model, and $\bar{y}_{i}$ is the average value of the numerical simulation results.

MOGA is an extension of the genetic algorithm that solves multi-objective optimization problems. It is widely used in multi-objective optimization problems because of its global search characteristics. The details of the parameter definitions are summarized in Table 3.

\subsection{Results and Discussion}

4.3.1. The Results of Model Reliability and Doe. The calculation is based on the verified finite element model. MCS-C and MSC-S use 28 sampling points to establish the approximate model, and MCS-M, MCC-C, and MCC-S use 32 sampling points to establish the RBF model. Tables $4-6$ show the design matrix of different designs of windowed structures. Table 7 shows the evaluation index of the RBF model. The results show that the accuracy of the model meets the engineering requirements. Among the three responses, the PCF shows very good fitting accuracy, its $R^{2}$ is close to 1 in different structures, and the MRE is within $1 \%$. For EA and SEA, $R^{2}>0.9$ and ARE is less than $5 \%$. Therefore, the RBF prediction model can replace the time-consuming numerical simulation model.

4.3.2. Optimization Results and Crashworthiness Analysis. The Pareto front of the windowed structures with different thicknesses and the crashworthiness index of the MC structures with the corresponding thicknesses are shown in Figure 13. An increase in SEA leads to an increase in PCF, and a decrease in PCF leads to a decrease in SEA. The design expectations of the two optimization objectives are contradictory. In addition, compared with the MC structures, all thicknesses of optimized windowed structures can achieve better crashworthiness. Regarding the shape of the windowed design, the square windowed design has a greater advantage in reducing the PCF, while the circular windowed design has a greater advantage for SEA when the thickness is less than $5 \mathrm{~mm}$. Note that in Figure 13(a), the Pareto solution is not found for MCS-M because the EA of MCS-M is lower than that of the MC when the wall thickness of the multi-cell structure is not more than $4 \mathrm{~mm}$. Similarly, in Figure 13(d), when the wall thickness of MCC-S is not more than $5.5 \mathrm{~mm}$, the EA of MCC-S cannot be increased with increasing SEA or decreasing PCF. The solution set that can obtain better design results without reducing EA is defined as the optimal solution, while the solution set that cannot obtain better design results is defined as the nonoptimal solution.

To further study the impact of window on the crashworthiness of structures, this study adopts the ideal optimal method [6]. The ideal optimal method is used to study the EA, SEA, and PCF of the windowed structures with the maximum SEA or the minimum PCF as a single objective, and the results are compared with those of MC. Figure 14 

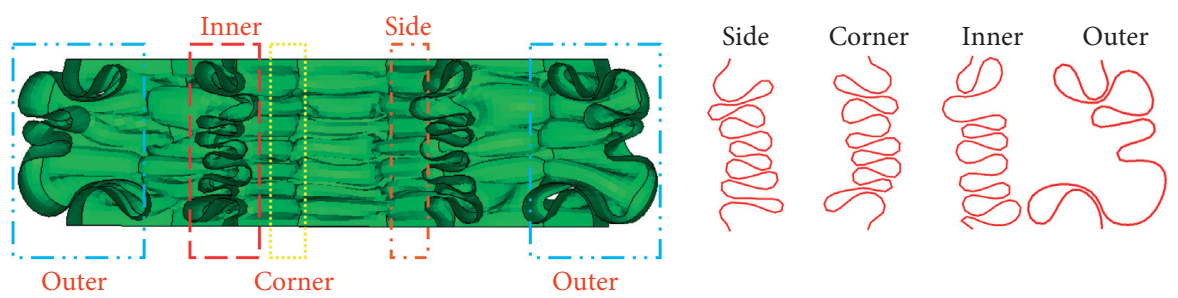

(a)
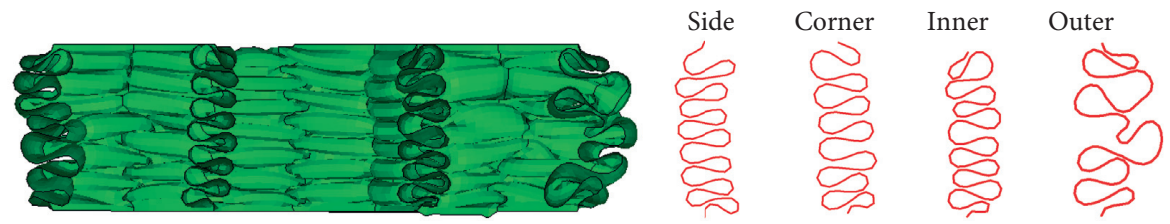

(b)
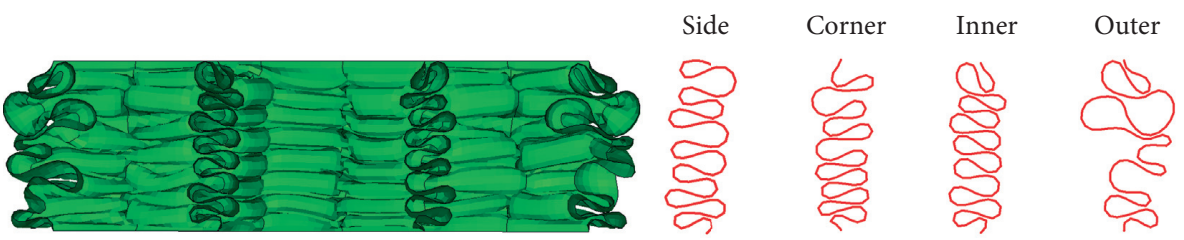

(c)
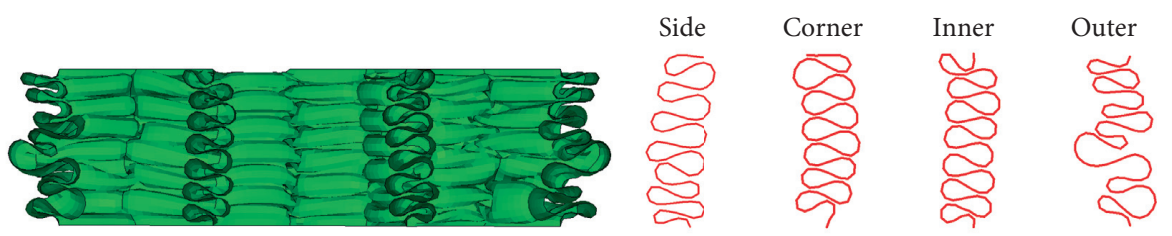

(d)
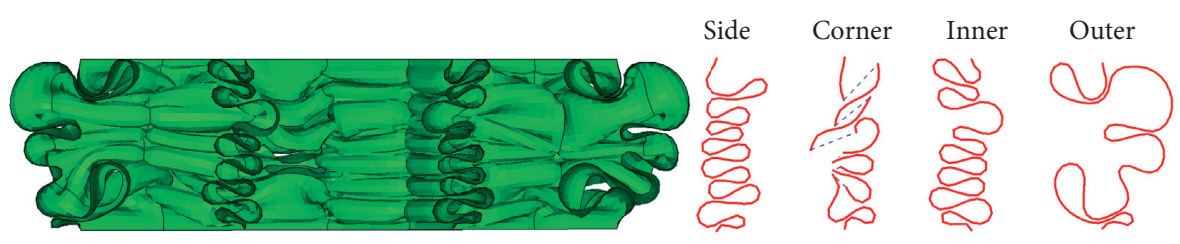

(e)
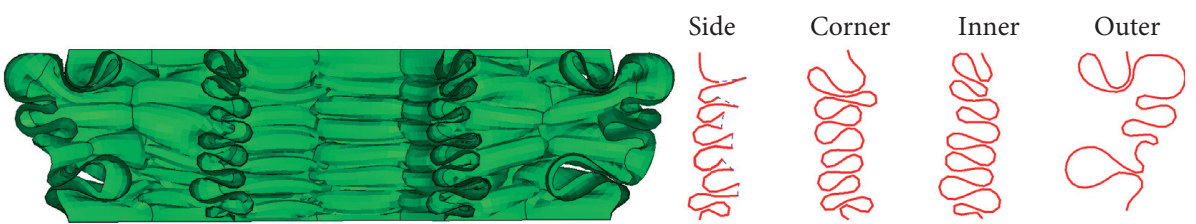

(f)

Figure 10: Comparison of the deformation modes of the different windowed structures. (a) MC. (b) MCS-C. (c) MCS-S. (d) MCS-M. (e) MCC-C. (f) MCC-S.

shows the improvement results of the crashworthiness indexes (SEA, EA, and PCF) at different thicknesses when selecting the optimal SEA. At this time, the thickness of the windowed structure is consistent with that of MC. The improvement in the crashworthiness of MCS-M and MCC-S with thicknesses of $4.5 \mathrm{~mm}$ and $5 \mathrm{~mm}$ is not shown in Figure 14 because their EA value is lower than that of the MC structures with the same thickness. Figure 14(a) shows the SEA improvement percentage of the MC structures with different windowed structures and different thicknesses.
Different windowed structures have different optimal matching thicknesses. When the thickness is $4 \mathrm{~mm}$, MCC-S can obtain the highest SEA, and when the thickness is $5.5 \mathrm{~mm}$ and $6 \mathrm{~mm}$, MCC-C has the greatest effect on the SEA. When the thickness is $4.5 \mathrm{~mm}$ and $5 \mathrm{~mm}$, MCC-C has the greatest effect on the SEA. With increasing thickness, the influence of MCC-C and MCC-S on the SEA decreases. The SEA of MCS-S at $5.5 \mathrm{~mm}$ is higher than that of other structures, and when the thickness is $6 \mathrm{~mm}$, MCS-C has the optimal SEA of windowed structures. Additionally, the effect 


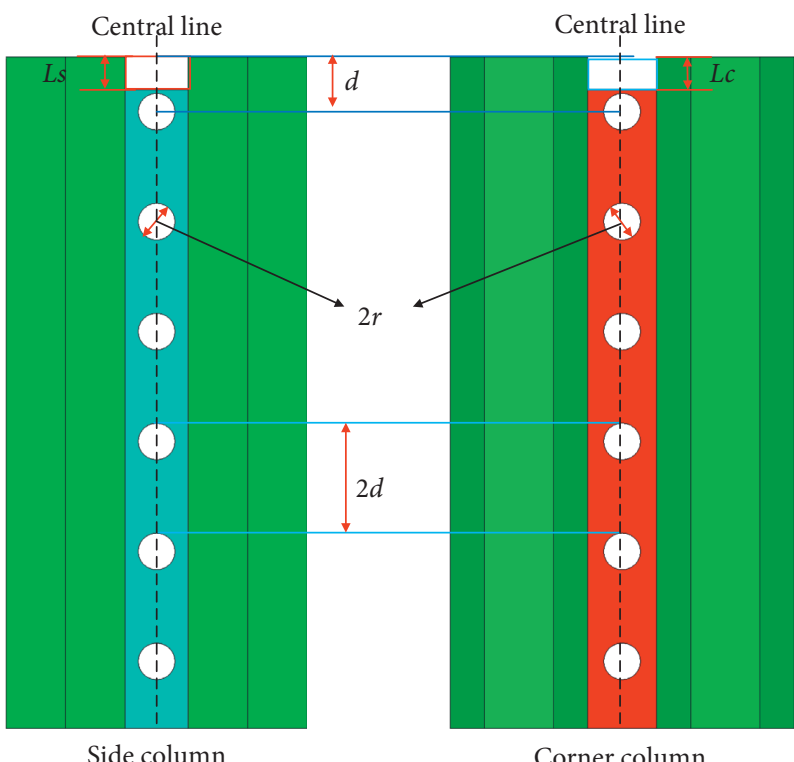

FIgURE 11: Variable distribution of windowed structures.

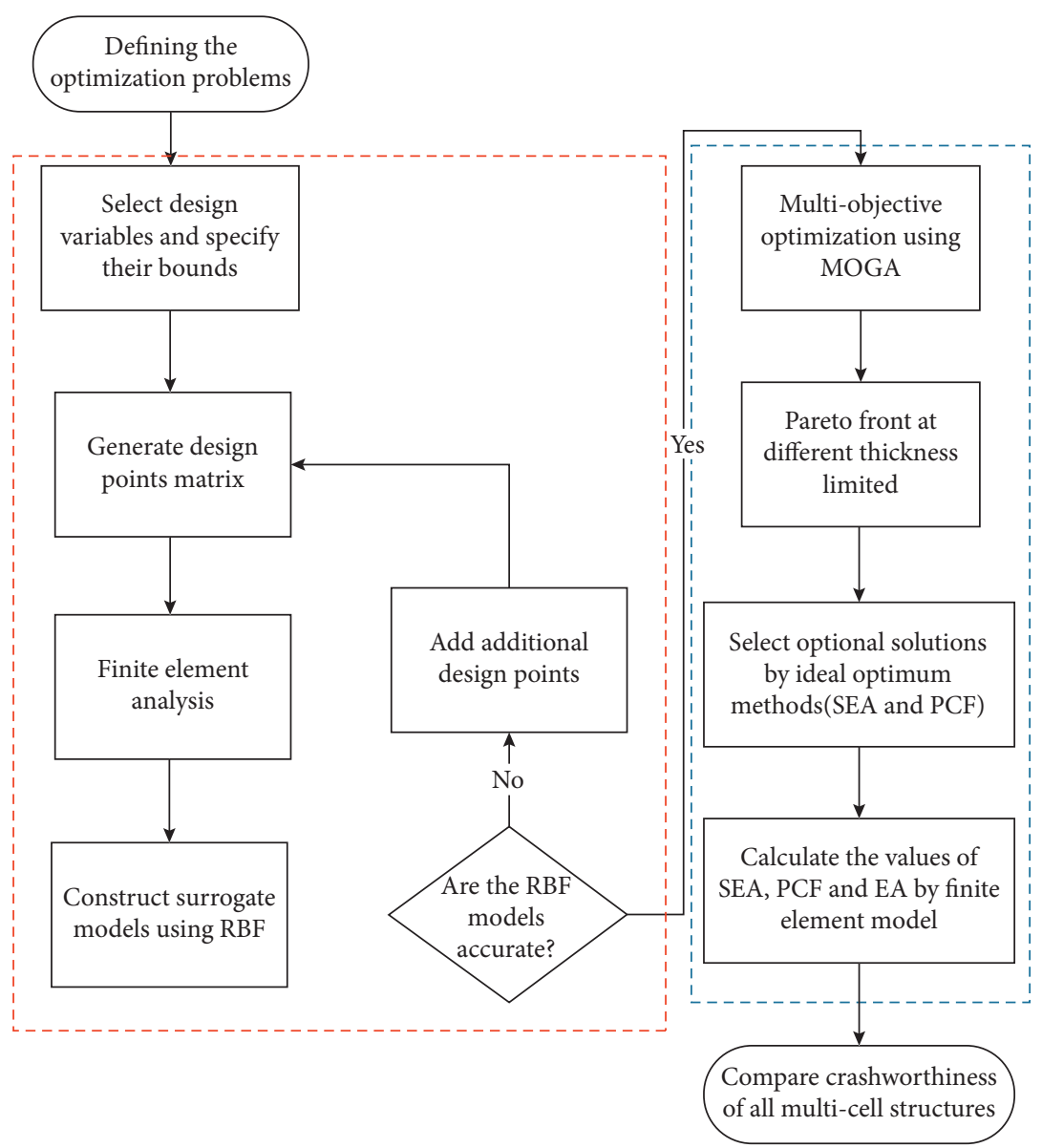

FIGURE 12: Flow chart of the research procedure.

of the windowed structure on the EA is similar to that on the SEA (Figure 14(c)). Figure 14(b) shows the effect of the window structure on the PCF under different thicknesses.
MCC-C and MCC-S have little effect on PCF, but the square structures greatly influence the PCF. In the case of the SEA as a single optimization, the square windowed design is more 
TABle 3: Parameter definitions of the MOGA.

\begin{tabular}{lc}
\hline Parameter & Value \\
\hline Maximum iteration & 50 \\
Minimum iteration & 25 \\
Population size & 70 \\
Constraint violation (\%) & 0.1 \\
Nondominated points & 500 \\
Mutation rate & 0.01 \\
Elite population (\%) & 10 \\
\hline
\end{tabular}

TABle 4: Design matrixes of MCS-C and MCS-S.

\begin{tabular}{|c|c|c|c|c|c|c|c|c|c|}
\hline \multirow{2}{*}{ No. } & \multicolumn{3}{|c|}{ Parameters } & \multicolumn{3}{|c|}{ Responses (MCS-C, $L s=0 \mathrm{~mm}$ ) } & \multicolumn{3}{|c|}{ Responses (MCS-S, $L c=0 \mathrm{~mm}$ ) } \\
\hline & $L c(\mathrm{~mm})$ & Ls $(\mathrm{mm})$ & $t(\mathrm{~mm})$ & $\operatorname{PCF}(\mathrm{kN})$ & $\mathrm{EA}(\mathrm{kJ})$ & SEA $(\mathrm{kJ} / \mathrm{kg})$ & $\mathrm{PCF}(\mathrm{kN})$ & $\mathrm{EA}(\mathrm{kJ})$ & $\mathrm{SEA}(\mathrm{kJ} / \mathrm{kg})$ \\
\hline 1 & 10 & 10 & 4 & 1035.92 & 279.943 & 30.29 & 1046.39 & 285.05 & 30.84 \\
\hline 2 & 10 & 10 & 6 & 1684.28 & 561.559 & 40.52 & 1694.84 & 540.73 & 38.99 \\
\hline 3 & 70 & 70 & 4 & 1002.34 & 270.632 & 29.51 & 1010.57 & 269.96 & 29.42 \\
\hline 4 & 70 & 70 & 6 & 1591.99 & 518.609 & 37.72 & 1609.92 & 527.93 & 38.34 \\
\hline 5 & 52.50 & 48.81 & 4.03 & 1005.97 & 270.60 & 29.19 & 1013.10 & 273.95 & 29.52 \\
\hline 6 & 42.73 & 44.83 & 4.17 & 1042.04 & 278.42 & 29.05 & 1051.27 & 281.98 & 29.41 \\
\hline 7 & 37.49 & 35.00 & 5.06 & 1302.91 & 396.76 & 34.08 & 1319.33 & 397.70 & 34.13 \\
\hline 8 & 67.50 & 53.47 & 4.42 & 1119.21 & 311.46 & 30.70 & 1123.63 & 316.36 & 31.10 \\
\hline 9 & 26.31 & 32.73 & 5.27 & 1388.74 & 438.26 & 36.07 & 1389.99 & 428.52 & 35.28 \\
\hline 10 & 49.21 & 68.54 & 4.53 & 1145.37 & 326.96 & 31.38 & 1160.21 & 319.79 & 30.75 \\
\hline 11 & 38.85 & 27.97 & 5.75 & 1516.65 & 489.61 & 36.99 & 1556.94 & 518.98 & 39.14 \\
\hline 12 & 53.49 & 52.12 & 4.20 & 1052.93 & 289.82 & 30.02 & 1061.57 & 290.08 & 30.03 \\
\hline 13 & 33.55 & 65.78 & 5.96 & 1596.36 & 527.28 & 38.40 & 1595.53 & 492.26 & 35.97 \\
\hline 14 & 28.54 & 62.87 & 4.72 & 1214.37 & 363.54 & 33.40 & 1212.64 & 343.22 & 31.65 \\
\hline 15 & 23.47 & 30.59 & 5.09 & 1339.52 & 408.90 & 34.80 & 1338.13 & 408.02 & 34.75 \\
\hline 16 & 58.36 & 38.49 & 4.95 & 1266.29 & 373.40 & 32.89 & 1280.89 & 396.30 & 34.79 \\
\hline 17 & 60.37 & 60.00 & 5.41 & 1405.21 & 420.39 & 33.85 & 1419.17 & 422.67 & 34.00 \\
\hline 18 & 65.32 & 27.34 & 4.61 & 1171.57 & 338.17 & 31.99 & 1193.60 & 347.84 & 32.73 \\
\hline 19 & 17.12 & 21.80 & 5.20 & 1392.99 & 423.50 & 35.28 & 1394.84 & 418.16 & 34.85 \\
\hline 20 & 22.33 & 10.32 & 5.51 & 1479.74 & 482.23 & 37.92 & 1527.15 & 475.68 & 37.34 \\
\hline 21 & 64.84 & 13.55 & 4.36 & 1100.86 & 303.69 & 30.37 & 1148.05 & 320.61 & 31.84 \\
\hline 22 & 40.78 & 40.76 & 5.78 & 1524.83 & 491.07 & 36.90 & 1543.59 & 506.58 & 38.05 \\
\hline 23 & 45.99 & 56.35 & 5.63 & 1471.38 & 476.08 & 36.79 & 1486.69 & 459.91 & 35.56 \\
\hline 24 & 14.30 & 60.99 & 4.91 & 1306.37 & 399.77 & 35.25 & 1268.44 & 366.37 & 32.48 \\
\hline 25 & 10.59 & 19.99 & 5.89 & 1645.83 & 542.63 & 39.85 & 1630.56 & 525.31 & 38.62 \\
\hline 26 & 30.47 & 46.71 & 4.75 & 1219.95 & 364.37 & 33.29 & 1218.54 & 353.76 & 32.37 \\
\hline 27 & 19.17 & 15.86 & 5.43 & 1462.50 & 465.71 & 37.15 & 1486.29 & 470.26 & 37.49 \\
\hline 28 & 55.76 & 24.17 & 4.32 & 1087.27 & 307.07 & 30.94 & 1112.39 & 310.45 & 31.15 \\
\hline
\end{tabular}

important for reducing the PCF, while the circular windowed design controls the deformation of the structure, improving the SEA and EA.

Figure 15 shows the improvement results of crashworthiness indexes (SEA and PCF) at different thicknesses when selecting the optimal PCF. The structure needs to ensure the EA requirements while reducing the $\mathrm{PCF}$. Therefore, the EA of the optimal PCF structure is the EA of MC structure under different thickness constraints. Under this optimization result, the EA of different windowed structures is consistent. In Figure 15(a), the windowed structure can reduce the PCF by three levels. MCS-M is the first level, which can reduce the PCF by up to $17 \%$. The second level and the third level are the square windowed design and circle windowed design, respectively. However, in the improvement of the SEA, the opposite result is presented. The SEA of the circular windowed design is the highest, while that of MCS-M is the lowest.
Single objective optimal results show that MCS-M is a better choice to reduce PCF, and MCC-C is a better choice to increase SEA and EA. The most effective structure to improve SEA is MCC-C with the thickness limit of $5 \mathrm{~mm}$ (Figure 14(a)), and the parameters $r$ and $d$ are $5 \mathrm{~mm}$ and $45 \mathrm{~mm}$, respectively. The most effective structure to reduce PCF is MCS-M with the thickness limit of $5 \mathrm{~mm}$ (Figure 15(a)), and the parameters $L c$ and $L s$ are $61.6 \mathrm{~mm}$ and $60.9 \mathrm{~mm}$, respectively. The results of FEM and RBF are shown in Table 8 . It can be seen that the percent errors were within an acceptable range, hence the optimized results were validated. In general, in the windowed structure studied in this study, the front-end windowed design has obvious advantages in reducing the PCF, while the circular windowed design easily improves the SEA and EA of the multi-cell structure. However, in some cases, the windowed design can lead to a reduced EA, such as when 
TABle 5: Design matrixes of MCS-M.

\begin{tabular}{|c|c|c|c|c|c|c|}
\hline \multirow{2}{*}{ No. } & \multicolumn{3}{|c|}{ Parameters } & \multicolumn{3}{|c|}{ Responses } \\
\hline & $L c(\mathrm{~mm})$ & $L s(\mathrm{~mm})$ & $t(\mathrm{~mm})$ & PCF $(\mathrm{kN})$ & EA $(\mathrm{kJ})$ & SEA $(\mathrm{kJ} / \mathrm{kg})$ \\
\hline 1 & 10.00 & 10.00 & 4.00 & 988.87 & 272.83 & 29.56 \\
\hline 2 & 10.00 & 70.00 & 4.00 & 959.84 & 272.23 & 29.71 \\
\hline 3 & 10.00 & 10.00 & 6.00 & 1618.84 & 553.98 & 40.00 \\
\hline 4 & 10.00 & 70.00 & 6.00 & 1546.22 & 507.16 & 36.88 \\
\hline 5 & 70.00 & 10.00 & 4.00 & 954.73 & 267.89 & 29.25 \\
\hline 6 & 70.00 & 70.00 & 4.00 & 916.28 & 261.95 & 28.81 \\
\hline 7 & 70.00 & 10.00 & 6.00 & 1533.38 & 509.58 & 37.09 \\
\hline 8 & 70.00 & 70.00 & 6.00 & 1543.96 & 532.79 & 39.06 \\
\hline 9 & 52.50 & 48.81 & 4.03 & 918.40 & 270.90 & 29.38 \\
\hline 10 & 42.73 & 44.83 & 4.17 & 954.96 & 283.51 & 29.75 \\
\hline 11 & 37.49 & 35.00 & 5.06 & 1197.25 & 396.26 & 34.19 \\
\hline 12 & 67.50 & 53.47 & 4.42 & 1019.58 & 314.93 & 31.24 \\
\hline 13 & 26.31 & 32.73 & 5.27 & 1277.67 & 417.91 & 34.54 \\
\hline 14 & 49.21 & 68.54 & 4.53 & 1050.34 & 332.43 & 32.18 \\
\hline 15 & 38.85 & 27.97 & 5.75 & 1405.80 & 486.55 & 36.89 \\
\hline 16 & 53.49 & 52.12 & 4.20 & 963.36 & 290.45 & 30.29 \\
\hline 17 & 33.55 & 65.78 & 5.96 & 1462.47 & 527.55 & 38.73 \\
\hline 18 & 28.54 & 62.87 & 4.72 & 1119.94 & 358.88 & 33.23 \\
\hline 19 & 23.47 & 30.59 & 5.09 & 1235.83 & 402.26 & 34.35 \\
\hline 20 & 58.36 & 38.49 & 4.95 & 1163.17 & 379.75 & 33.61 \\
\hline 21 & 60.37 & 60.00 & 5.41 & 1278.98 & 426.53 & 34.59 \\
\hline 22 & 65.32 & 27.34 & 4.61 & 1090.56 & 337.43 & 32.01 \\
\hline 23 & 17.12 & 21.80 & 5.20 & 1306.32 & 415.42 & 34.70 \\
\hline 24 & 22.33 & 10.32 & 5.51 & 1415.13 & 474.42 & 37.36 \\
\hline 25 & 64.84 & 13.55 & 4.36 & 1047.17 & 309.42 & 31.00 \\
\hline 26 & 40.78 & 40.76 & 5.78 & 1394.65 & 495.57 & 37.43 \\
\hline 27 & 45.99 & 56.35 & 5.63 & 1341.13 & 461.20 & 35.89 \\
\hline 28 & 14.30 & 60.99 & 4.91 & 1206.45 & 387.16 & 34.38 \\
\hline 29 & 10.59 & 19.99 & 5.89 & 1548.23 & 538.87 & 39.68 \\
\hline 30 & 30.47 & 46.71 & 4.75 & 1118.14 & 362.43 & 33.31 \\
\hline 31 & 19.17 & 15.86 & 5.43 & 1385.69 & 450.45 & 36.01 \\
\hline 32 & 55.76 & 24.17 & 4.32 & 1013.95 & 306.54 & 31.00 \\
\hline
\end{tabular}

TABle 6: Design matrixes of MCC-C and MCC-S.

\begin{tabular}{|c|c|c|c|c|c|c|c|c|c|}
\hline \multirow{2}{*}{ No. } & \multicolumn{3}{|c|}{ Parameters } & \multicolumn{3}{|c|}{ Responses (MCC-C) } & \multicolumn{3}{|c|}{ Responses (MCC-S) } \\
\hline & $d(\mathrm{~mm})$ & $r(\mathrm{~mm})$ & $t(\mathrm{~mm})$ & PCF $(\mathrm{kN})$ & EA $(\mathrm{kJ})$ & SEA (kJ/kg) & PCF $(\mathrm{kN})$ & EA (kJ) & SEA $(\mathrm{kJ} / \mathrm{kg})$ \\
\hline 1 & 30.00 & 5.00 & 4.00 & 1078.88 & 271.99 & 29.42 & 1077.43 & 280.70 & 30.36 \\
\hline 2 & 45.00 & 5.00 & 4.00 & 1079.98 & 274.03 & 29.64 & 1078.93 & 274.99 & 29.74 \\
\hline 3 & 30.00 & 25.00 & 4.00 & 1013.82 & 254.03 & 28.22 & 1016.24 & 257.76 & 28.63 \\
\hline 4 & 45.00 & 25.00 & 4.00 & 1022.07 & 262.88 & 29.20 & 1024.56 & 267.56 & 29.72 \\
\hline 5 & 30.00 & 5.00 & 6.00 & 1722.81 & 497.61 & 35.95 & 1720.99 & 515.95 & 37.20 \\
\hline 6 & 45.00 & 5.00 & 6.00 & 1726.22 & 522.26 & 37.65 & 1724.51 & 528.78 & 38.12 \\
\hline 7 & 30.00 & 25.00 & 6.00 & 1608.57 & 453.67 & 33.61 & 1613.25 & 453.10 & 33.56 \\
\hline 8 & 45.00 & 25.00 & 6.00 & 1633.20 & 480.62 & 35.60 & 1637.70 & 475.99 & 35.26 \\
\hline 9 & 39.70 & 5.35 & 5.42 & 1529.60 & 441.32 & 35.25 & 1526.37 & 408.18 & 32.60 \\
\hline 10 & 38.71 & 6.66 & 5.09 & 1421.13 & 402.25 & 34.21 & 1417.49 & 410.01 & 34.86 \\
\hline 11 & 36.25 & 15.57 & 4.92 & 1328.63 & 361.82 & 32.13 & 1326.67 & 361.39 & 32.10 \\
\hline 12 & 40.87 & 9.24 & 5.92 & 1680.03 & 502.12 & 36.81 & 1678.38 & 481.58 & 35.31 \\
\hline 13 & 35.68 & 17.70 & 4.54 & 1205.83 & 317.81 & 30.65 & 1204.72 & 321.60 & 31.01 \\
\hline 14 & 44.64 & 10.32 & 5.31 & 1471.09 & 413.97 & 33.88 & 1469.19 & 412.63 & 33.77 \\
\hline 15 & 34.49 & 22.50 & 4.96 & 1311.45 & 349.45 & 31.12 & 1312.00 & 358.79 & 31.95 \\
\hline 16 & 40.53 & 7.02 & 5.45 & 1533.03 & 385.30 & 30.63 & 1530.23 & 393.96 & 31.32 \\
\hline 17 & 43.95 & 24.62 & 4.78 & 1254.57 & 335.38 & 31.11 & 1254.78 & 347.12 & 32.20 \\
\hline 18 & 43.22 & 12.22 & 4.62 & 1247.59 & 344.09 & 32.40 & 1245.24 & 343.46 & 32.34 \\
\hline 19 & 35.15 & 15.94 & 4.45 & 1182.79 & 315.48 & 30.99 & 1181.38 & 319.15 & 31.35 \\
\hline 20 & 37.12 & 14.45 & 5.61 & 1550.62 & 442.83 & 34.41 & 1550.49 & 448.72 & 34.87 \\
\hline
\end{tabular}


TABle 6: Continued.

\begin{tabular}{|c|c|c|c|c|c|c|c|c|c|}
\hline \multirow{2}{*}{ No. } & \multicolumn{3}{|c|}{ Parameters } & \multicolumn{3}{|c|}{ Responses (MCC-C) } & \multicolumn{3}{|c|}{ Responses (MCC-S) } \\
\hline & $d(\mathrm{~mm})$ & $r(\mathrm{~mm})$ & $t(\mathrm{~mm})$ & PCF $(\mathrm{kN})$ & $\mathrm{EA}(\mathrm{kJ})$ & SEA $(\mathrm{kJ} / \mathrm{kg})$ & PCF $(\mathrm{kN})$ & EA $(\mathrm{kJ})$ & SEA $(\mathrm{kJ} / \mathrm{kg})$ \\
\hline 21 & 42.50 & 19.11 & 5.68 & 1552.54 & 447.16 & 34.58 & 1552.18 & 446.51 & 34.53 \\
\hline 22 & 34.33 & 11.09 & 5.84 & 1638.40 & 459.97 & 34.20 & 1639.70 & 492.20 & 36.59 \\
\hline 23 & 32.95 & 17.00 & 4.24 & 1111.48 & 287.35 & 29.68 & 1109.89 & 298.20 & 30.81 \\
\hline 24 & 30.08 & 20.12 & 4.41 & 1147.83 & 307.98 & 30.71 & 1147.11 & 310.51 & 30.96 \\
\hline 25 & 30.89 & 8.59 & 5.83 & 1642.83 & 467.60 & 34.79 & 1642.97 & 482.27 & 35.88 \\
\hline 26 & 37.69 & 22.83 & 5.03 & 1334.49 & 369.71 & 32.55 & 1333.90 & 387.21 & 34.09 \\
\hline 27 & 41.59 & 21.27 & 5.20 & 1393.99 & 382.07 & 32.41 & 1392.18 & 376.24 & 31.91 \\
\hline 28 & 42.75 & 14.11 & 4.14 & 1096.56 & 297.93 & 31.36 & 1095.06 & 287.58 & 30.27 \\
\hline 29 & 32.50 & 23.93 & 4.02 & 1025.85 & 256.25 & 28.25 & 1026.13 & 257.56 & 28.40 \\
\hline 30 & 39.18 & 12.50 & 4.68 & 1268.94 & 349.65 & 32.50 & 1266.01 & 349.20 & 32.45 \\
\hline 31 & 31.47 & 19.32 & 4.31 & 1121.68 & 303.96 & 31.02 & 1120.59 & 302.19 & 30.84 \\
\hline 32 & 33.54 & 8.21 & 5.53 & 1548.15 & 438.16 & 34.37 & 1546.44 & 436.88 & 34.26 \\
\hline
\end{tabular}

TABle 7: Accuracy of the approximate models.

\begin{tabular}{ccccccc}
\hline \multicolumn{2}{c}{ Evaluation index } & MCS-C & MCS-S & MCS-M & MCC-C & MCC-S \\
\hline \multirow{2}{*}{$R^{2}$} & PCF & 0.9945 & 0.9987 & 0.9987 & 0.9915 & 0.9910 \\
& EA & 0.9849 & 0.9739 & 0.9969 & 0.9571 & 0.9611 \\
\multirow{3}{*}{ MRE (\%) } & SEA & 0.9249 & 0.9077 & 0.9752 & 0.9313 \\
& PCF & 5.03 & 2.51 & 1.50 & 0.57 \\
\multirow{4}{*}{ ARE (\%) } & EA & 9.10 & 7.25 & 1.66 & 9.43 & 10.30 \\
& SEA & 9.12 & 9.35 & 0.26 & 0.20 & 7.91 \\
& PCF & 0.46 & 0.33 & 0.73 & 3.02 & 0.25 \\
& EA & 1.69 & 2.55 & 0.74 & 3.03 & 2.99 \\
\hline
\end{tabular}

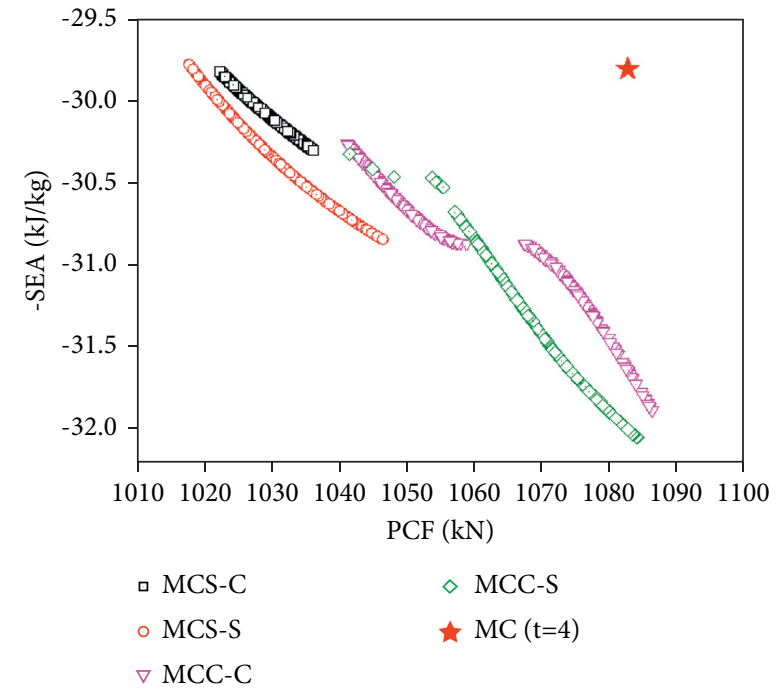

(a)

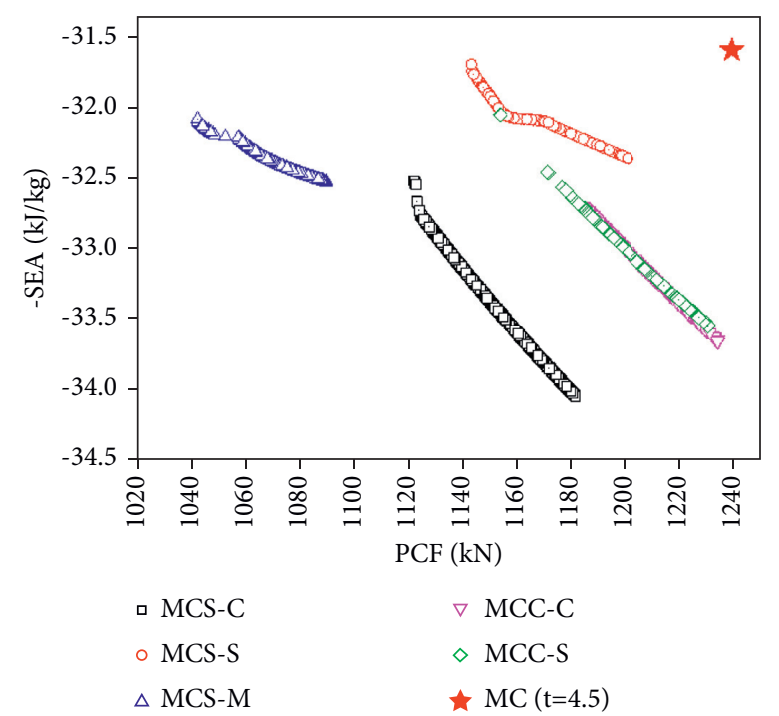

(b)

FIgURE 13: Continued. 


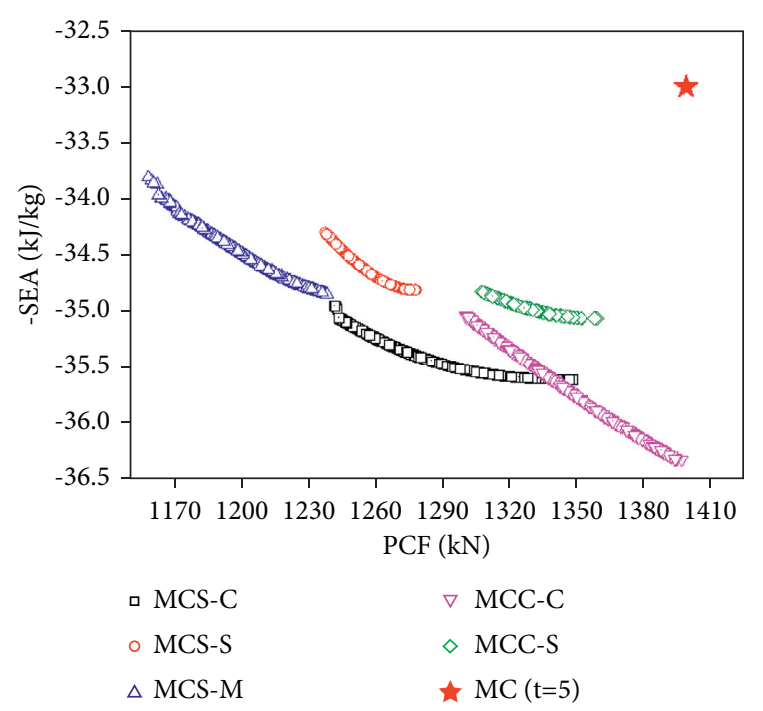

(c)
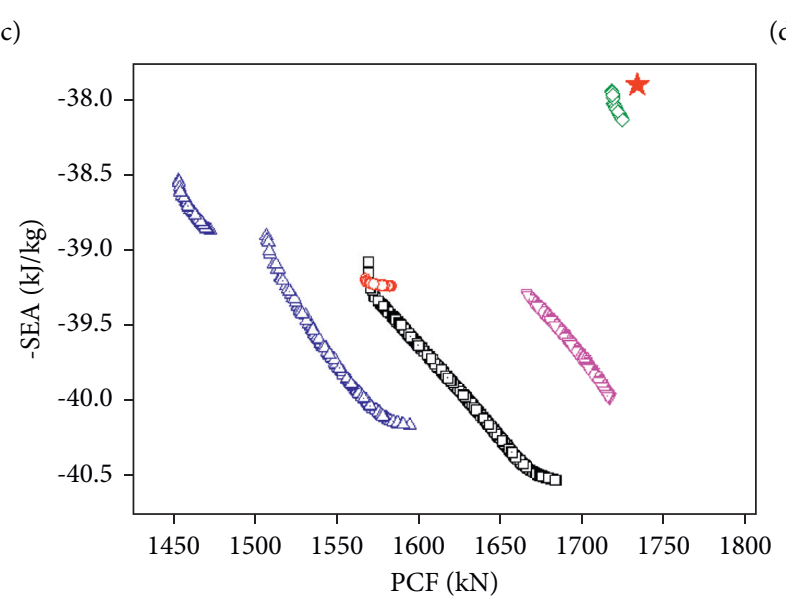
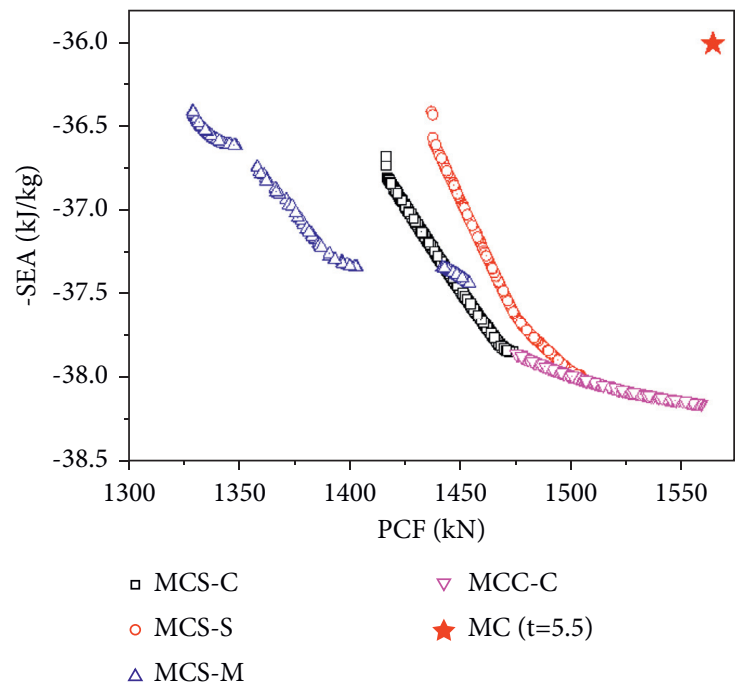

(d)
a MCS-C
$\nabla$ MCC-C
- MCS-S
$\diamond \mathrm{MCS}-\mathrm{S}$
$\triangle \mathrm{MCS}-\mathrm{M}$
$\star \mathrm{MC}(\mathrm{t}=6)$

(e)

Figure 13: Pareto solutions for the windowed tubes with different thicknesses. (a) $4 \mathrm{~mm}$. (b) $4.5 \mathrm{~mm}$. (c) $5 \mathrm{~mm}$. (d) $5.5 \mathrm{~mm}$. (e) $6 \mathrm{~mm}$.

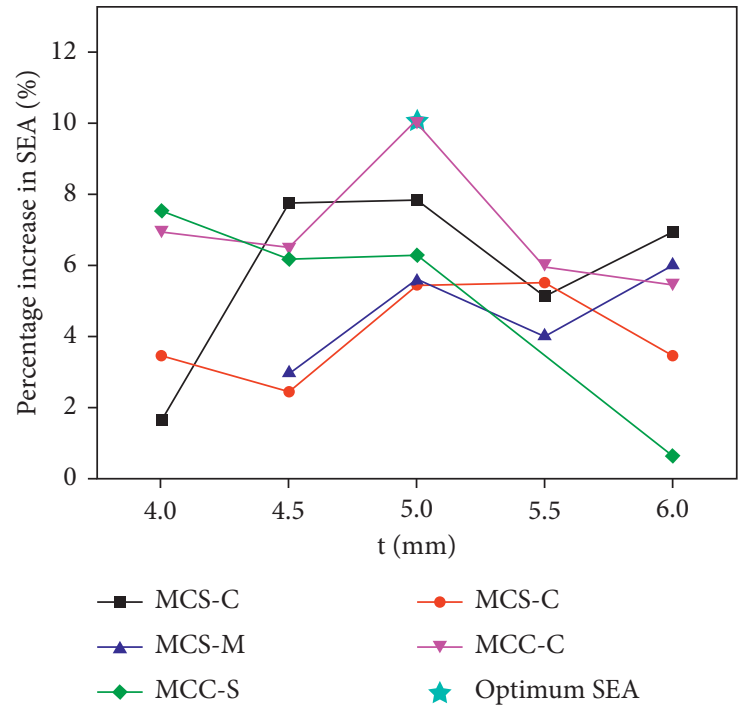

(a)

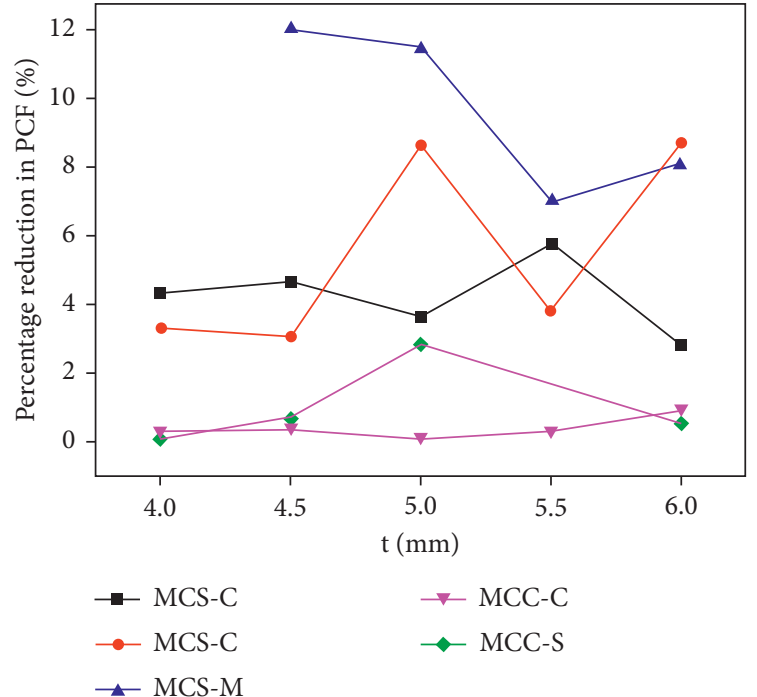

(b)

Figure 14: Continued. 


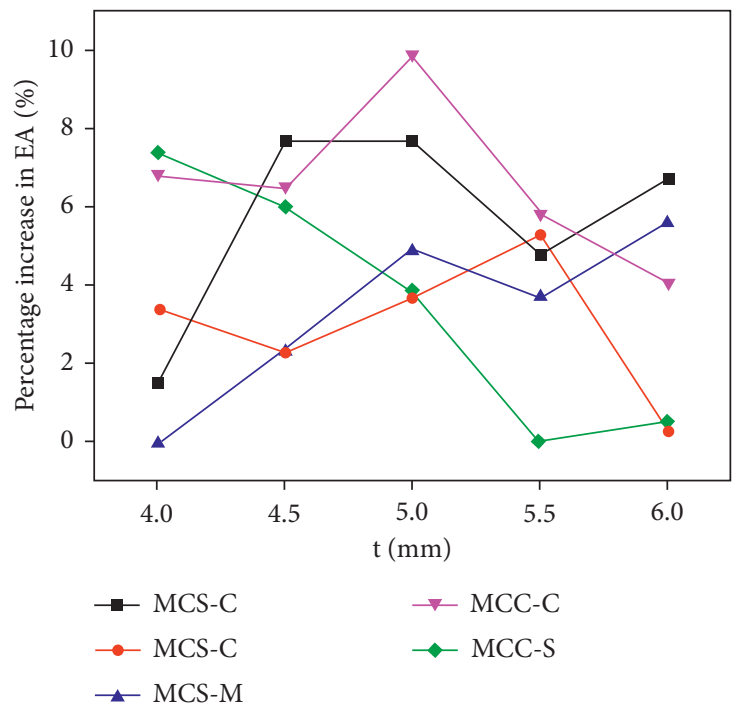

(c)

FIGURE 14: Improvement in the crashworthiness of different windowed structures under optimal SEA. (a) SEA. (b) PCF. (c) EA.

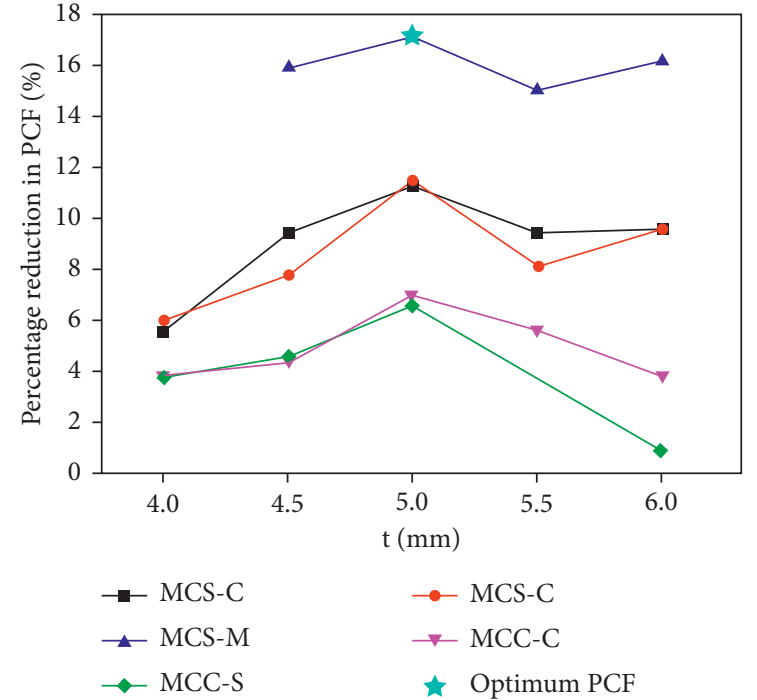

(a)

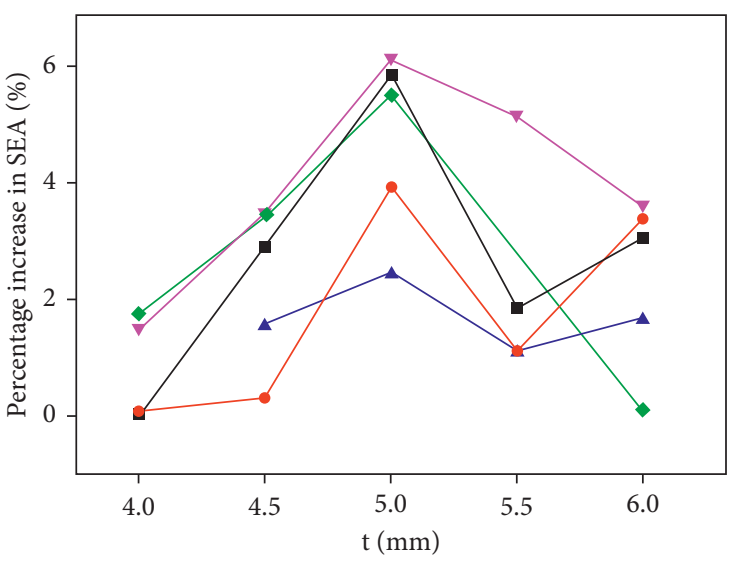

$\rightarrow$ MCS-C

$\rightarrow$ MCC-C

- MCS-S

- MCC-S

(b)

Figure 15: Improvement in the crashworthiness of different windowed structures under the optimal PCF. (a) PCF. (b) SEA.

TABLE 8: Verification of optimal solution.

\begin{tabular}{|c|c|c|c|c|}
\hline \multicolumn{2}{|c|}{ Parameter } & PCF & EA & SEA \\
\hline \multirow{3}{*}{ MCS-M } & Predicted & 1158.40 & 381.37 & 33.81 \\
\hline & FEM & 1171.59 & 384.51 & 33.90 \\
\hline & Error (\%) & -1.13 & -0.81 & -0.26 \\
\hline \multirow{3}{*}{ MCC-C } & Predicted & 1396.87 & 419.53 & 36.32 \\
\hline & FEM & 1393.64 & 403.21 & 35.03 \\
\hline & Error (\%) & 0.23 & 4.04 & 3.68 \\
\hline
\end{tabular}


the thickness of the MCC-S is $5.5 \mathrm{~mm}$. Therefore, the thickness is an important reference factor in the windowed design.

\section{Conclusion}

In this study, windowed design is carried out in different regions and different positions (front end and middle) of multi-cell structures to form windowed structures. The accuracy of the finite element simulation is verified by experiments. On this basis, five kinds of windowed structures are selected for comparison of their crashworthiness. The optimal crashworthiness of different structures at different thicknesses is compared by using the multi-objective optimization method. The main conclusions of this study are as follows:

(1) The introduction of the windowed design in the multi-cell structures can reduce the PCF and increase the EA and SEA, different from the single-cell window tubes.

(2) The windowed design can affect the deformation mode of multi-cell structures. The window design adjusts the deformation mode by changing the stress distribution of the structure under impact load to produce more folds. This is the key factor for improving the crashworthiness of multi-cell structures and addressing the relationship between deformation regions.

(3) The windowed design is sensitive to the thickness of the structure. When the thickness is $5 \mathrm{~mm}$, the windowed structure studied in this study can improve the crashworthiness the most. The effect of the window design in different regions is not consistent. In most cases, the effect of the windowed design on the side column is lower than that on the corner column. The windowed design has good potential for improving the crashworthiness of thin-walled structures and achieving a lightweight design.

\section{Data Availability}

The data used to support the findings of this study are available from the corresponding author upon request.

\section{Conflicts of Interest}

The authors declare that they have no conflicts of interest.

\section{Acknowledgments}

This work was supported by the National Natural Science Foundation of China (No. 51675537), National Key Research and Development Program of China (No. 2016YFB1200505), and the Independent Exploration and Innovation Platform and Talent Plan of Hunan Province (No. 2019RS3018). The financial support is gratefully acknowledged.

\section{References}

[1] A. Baroutaji, M. Sajjia, and A.-G. Olabi, "On the crashworthiness performance of thin-walled energy absorbers: recent advances and future developments," Thin-Walled Structures, vol. 118, pp. 137-163, 2017.

[2] J. Marzbanradand and M. R. Ebrahimi, "Multi-Objective Optimization of aluminum hollow tubes for vehicle crash energy absorption using a genetic algorithm and neural networks," Thin-Walled Structures, vol. 49, no. 12, pp. 1605-1615, 2011.

[3] H.-S. Kim, "New extruded multi-cell aluminum profile for maximum crash energy," Thin-Walled Structures, vol. 40, pp. 311-327, 2002.

[4] T. N. Tran and A. Baroutaji, "Crashworthiness optimal design of multi-cell triangular tubes under axial and oblique impact loading," Engineering Failure Analysis, vol. 93, pp. 241-256, 2018.

[5] T. Tran, S. Hou, X. Han, W. Tan, and T. N. Nguyen, "Theoretical prediction and crashworthiness optimization of multi-cell triangular tubes," Thin-Walled Structures, vol. 82, pp. 183-195, 2014.

[6] G. Sun, X. Tian, J. Fang, F. Xu, G. Li, and X. Huang, "Dynamical bending analysis and optimization design for functionally graded thickness (FGT) tube," International Journal of Impact Engineering, vol. 78, pp. 128-137, 2015.

[7] M. Abbasi, S. Reddy, A. Ghafari-Nazariand, and M. Fard, "Multiobjective crashworthiness optimization of multi-cornered thin-walled sheet metal members," Thin-Walled Structures, vol. 89, pp. 31-41, 2015.

[8] Z. Li, W. Ma, P. Xu, and S. Yao, "Crashworthiness of multicell circumferentially corrugated square tubes with cosine and triangular configurations," International Journal of Mechanical Sciences, vol. 165, Article ID 105205, 2020.

[9] Z. X. Li, S. G. Yao, W. Ma, P. XuandQ, and W. Che, "Energyabsorption characteristics of a circumferentially corrugated square tube with a cosine profile," Thin-Walled Structures, vol. 135, pp. 385-399, 2019.

[10] W. Ma, S. Xie, and Z. Li, "Mechanical performance of bioinspired corrugated tubes with varying vertex configurations," International Journal of Mechanical Sciences, vol. 172, Article ID 105399, 2020.

[11] I. Vimal Kannan and R. Rajkumar, "Deformation and energy absorption analysis of simple and multi-cell thin-walled tubes under quasi-static axial crushing," International Journal of Crashworthiness, vol. 25, no. 2, pp. 121-130, 2020.

[12] N. Qiu, Y. Gao, J. Fang, Z. Feng, G. Sun, and Q. Li, "Crashworthiness analysis and design of multi-cell hexagonal columns under multiple loading cases," Finite Elements in Analysis and Design, vol. 104, pp. 89-101, 2015.

[13] N. Qiu, Y. Gao, J. Fang, G. Sun, and N. H. Kim, “Topological design of multi-cell hexagonal tubes under axial and lateral loading cases using a modified particle swarm algorithm," Applied Mathematical Modelling, vol. 53, pp. 567-583, 2018.

[14] T. Tran, L. D. Hieu, and A. Baroutaji, "Theoretical and numerical crush analysis of multi-stage nested aluminium alloy tubular structures under axial impact loading," Engineering Structures, vol. 182, pp. 39-50, 2019.

[15] H. Saeidi Googarchin, M. Pasandidehpoor, A. Mahmoodi, and M. H. Shojaeefard, "Energy absorption analysis for tapered multi-cell tubes improved by foams: theoretical development and numerical simulation," Composite Structures, vol. 207, pp. 213-222, 2019.

[16] Y. Wang, Q. Guo, L. Wang, and H. Xu, "Evaluation of compression performance of APM aluminum foam-polymer 
filled pipes prepared via different epoxy resin bonding processes," Advances in Materials Science and Engineering, vol. 2019, Article ID 7978140, 10 pages, 2019.

[17] G. Cricrì, M. Perrella, and C. Calì, "Honeycomb failure processes under in-plane loading," Composites Part B: Engineering, vol. 45, no. 1, pp. 1079-1090, 2013.

[18] Z. Wang, J. Zhang, Z. Li, and C. Shi, "On the crashworthiness of bio-inspired hexagonal prismatic tubes under axial compression," International Journal of Mechanical Sciences, vol. 186, Article ID 105893, 2020.

[19] S. Xie, K. Jing, H. Zhou, and X. Liu, "Mechanical properties of Nomex honeycomb sandwich panels under dynamic impact," Composite Structures, vol. 235, Article ID 111814, 2020.

[20] S. Xie, Z. Feng, H. Zhou, and D. Wang, "Three-point bending behavior of Nomex honeycomb sandwich panels: experiment and simulation," Mechanics of Advanced Materials and Structures, vol. 28, no. 18, pp. 1917-1931, 2020.

[21] T. Pang, G. Zheng, J. Fang, D. Ruan, and G. Sun, "Energy absorption mechanism of axially-varying thickness (AVT) multicell thin-walled structures under out-of-plane loading," Engineering Structures, vol. 196, Article ID 109130, 2019.

[22] G. Zheng, T. Pang, G. Sun, S. Wu, and Q. Li, “Theoretical, numerical, and experimental study on laterally variable thickness (LVT) multi-cell tubes for crashworthiness," International Journal of Mechanical Sciences, vol. 118, pp. 283-297, 2016.

[23] R. Qin, J. Zhou, and B. Chen, "Crashworthiness design and multiobjective optimization for hexagon honeycomb structure with functionally graded thickness," Advances in Materials Science and Engineering, vol. 2019, Article ID 8938696, 13 pages, 2019.

[24] S. Xie, H. Li, C. Yang, and S. Yao, "Crashworthiness optimisation of a composite energy-absorbing structure for subway vehicles based on hybrid particle swarm optimisation," Structural and Multidisciplinary Optimization, vol. 58, no. 5, pp. 2291-2308, 2018.

[25] N. K. Gupta and S. K. Gupta, "Effect of annealing, size and cut-outs on axial collapse behaviour of circular tubes," International Journal of Mechanical Sciences, vol. 35, no. 7, pp. 597-613, 1993.

[26] S. Wang, Y. Peng, T. Wang, X. Chen, L. Hou, and H. Zhang, "The origami inspired optimization design to improve the crashworthiness of a multi-cell thin-walled structure for high speed train," International Journal of Mechanical Sciences, vol. 159, pp. 345-358, 2019.

[27] J. Zhou, C. Dong, B. Chen, and X. Niu, "Design and numerical simulation of pyramidal prefolded patterned thin-walled tubes," Advances in Materials Science and Engineering, vol. 2021, Article ID 6614381, 16 pages, 2021.

[28] Z. Li, S. Rakheja, and W.-B. Shangguan, "Study on crushing behaviors of foam-filled thin-walled square tubes with different types and number of initiators under multiple angle loads," Thin-Walled Structures, vol. 145, Article ID 106376, 2019.

[29] J. Song, "Numerical simulation on windowed tubes subjected to oblique impact loading and a new method for the design of obliquely loaded tubes," International Journal of Impact Engineering, vol. 54, pp. 192-205, 2013.

[30] J. Song, Y. Chen, and G. Lu, "Light-weight thin-walled structures with patterned windows under axial crushing," International Journal of Mechanical Sciences, vol. 66, pp. 239-248, 2013.

[31] J. Song and F. Guo, "A comparative study on the windowed and multi-cell square tubes under axial and oblique loading," Thin-Walled Structures, vol. 66, pp. 9-14, 2013.
[32] H. Nikkhah, A. Baroutaji, and A. G. Olabi, "Crashworthiness design and optimisation of windowed tubes under axial impact loading," Thin-Walled Structures, vol. 142, pp. 132-148, 2019.

[33] J. Chen, P. Xu, S. Yao, J. Xing, and Z. Hu, “The multi-objective structural optimisation design to improve the crashworthiness of a multi-cell structure for high-speed train," International Journal of Crashworthiness, vol. 26, pp. 1-10, 2020.

[34] S. Wang, Y. Peng, T. Wang, Q. Che, and P. Xu, "Collision performance and multi-objective robust optimization of a combined multi-cell thin-walled structure for high speed train,” Thin-Walled Structures, vol. 135, pp. 341-355, 2019.

[35] Y. Peng, W. Deng, P. Xu, and S. Yao, "Study on the collision performance of a composite energy-absorbing structure for subway vehicles," Thin-Walled Structures, vol. 94, pp. 663672, 2015.

[36] Y. Xiang, M. Wang, T. Yu, and L. Yang, "Key performance indicators of tubes and foam-filled tubes used as energy absorbers," International Journal of Applied Mechanics, vol. 7, no. 4, pp. 1-20, 2015.

[37] Z. Li, L. B. Duan, A. G. Cheng, Z. P. Yao, T. Chen, and W. Yao, "Lightweight and crashworthiness design of an electric vehicle using a six-sigma robust design optimization method," Engineering Optimization, vol. 51, no. 8, pp. 1393-1411, 2018.

[38] F. Li, W. Shen, X. Cai, L. Gao, and G. G. Wang, "A fast surrogate-assisted particle swarm optimization algorithm for computationally expensive problems," Applied Soft Computing, vol. 92, Article ID 106303, 2020.

[39] P. Xu, K. Xu, S. Yao et al., "Parameter study and multi-objective optimisation of an axisymmetric rectangular tube with diaphragms for subways," Thin-Walled Structures, vol. 136, pp. 186-199, 2019. 